https://helda.helsinki.fi

\title{
Physicochemical and rheo-mechanical properties of titanium dioxide reinforced sage seed gum nanohybrid hydrogel
}

\section{Oleyaei, Seyed Amir}

2018-10-15

Oleyaei , S A , Razavi , S M A \& Mikkonen, K S 2018 , ' Physicochemical and rheo-mechanical properties of titanium dioxide reinforced sage seed gum nanohybrid hydrogel ' , International Journal of Biological Macromolecules, vol. 118 , no. Part A, pp. 661-670 . https://doi.org/10.1016/j.jibiomac.2018.06.049

http://hdl.handle.net/10138/309177

https://doi.org/10.1016/j.ijbiomac.2018.06.049

cc_by_nc_nd

acceptedVersion

Downloaded from Helda, University of Helsinki institutional repository.

This is an electronic reprint of the original article.

This reprint may differ from the original in pagination and typographic detail.

Please cite the original version. 


\title{
Physicochemical and rheo-mechanical properties of titanium dioxide reinforced sage seed gum nanohybrid hydrogel
}

\author{
Seyed Amir Oleyaei ${ }^{\mathrm{a}}$, Seyed Mohammad Ali Razavi ${ }^{\mathrm{a}, *}$, Kirsi S. Mikkonen $^{\mathrm{b}}$ \\ ${ }^{\mathrm{a}}$ Food Hydrocolloids Research Centre, Department of Food Science and Technology, Ferdowsi \\ University of Mashhad (FUM), P.O. Box 91775-1163, Mashhad, Iran \\ ${ }^{\mathrm{b}}$ Department of Food and Nutrition, P.O. Box 66 (Agnes Sjöberginkatu 2), FI-00014, University of \\ Helsinki, Finland
}

\begin{abstract}
Sage seed gum (SSG) is a promising biopolymer candidate for utilization and substitution prevalent galactomannan gels of interest in soft biomaterial applications. Herein, physicochemical and rheo-mechanical properties of SSG matrix reinforced by various titanium dioxide $\left(\mathrm{TiO}_{2}\right)$ nanoparticles loading (0-25 wt\%) were monitored. Particle size and density of the nanocomposite increased with raising $\mathrm{TiO}_{2}$ content, due to the creation of more compact agglomerated and aggregated microstructure. Increasing the particle size resulted in lower electrophoretic mobility of $\mathrm{SSG}_{-} \mathrm{TiO}_{2}$ systems upon nanoparticles addition, confirmed the adsorption of $\mathrm{TiO}_{2}$ on the $\mathrm{SSG}$ macromolecule. Mechanical spectra of the SSG-based nanocomposites demonstrated a more solidlike behavior by lower frequency-dependent viscoelastic moduli, suggested a structural decoration of the nanohybrid gels discussed in terms of polymer bridging effect and formation of percolated matrix-particle superstructure. Crucial textural parameters improved with increasing $\mathrm{TiO}_{2}$ until a
\end{abstract}

*Corresponding author: Tel: +98-51-38805763, Fax: +98-51-38787430, Email: s.razavi@um.ac.ir 
critical level (15 wt\%), after which further increments in filler resulted in a reduction of hardness, adhesiveness and apparent modulus of elasticity. Deformation of rod-like junction zones acting as physical crosslinks in the system and fracture theory were used to explain the strain-stiffening and adhesive behavior of SSG-based gels, respectively. The nanocomposite gels with tunable functional properties might be ideal candidates for biomaterial industry.

Keywords: Biomaterial; Hydrogel; Galactomannan; Nanocomposite; Rheology; Titanium dioxide.

\section{Introduction}

Hydrogels are three-dimensional (3D) polymer networks containing large quantities of water or biological fluids, which have attracted much attention as functional soft materials. They are used for several applications ranging from biomedical to agricultural and food industries [1]. Hydrogels can also proffer novel opportunities for the design of more efficient polymer-based substances with applicable characteristics, by converting into the highly porous engineered scaffold, aerogel and thin film constructs [2-4]. Nowadays, there is a great consideration in developing special hydrogels from non-toxic natural hydrophilic polymers (hydrocolloids) with low cost and appropriate functionality. Galactomannan polysaccharides such as sage seed gum (SSG) are the ones which could meet these appeals. SSG with a 1.78-1.93:1 mannose/galactose ratio, 28-32\% uronic acids (as galacturonic acid equivalent) and the weight average molecular weight of $1.5 \times$

$10^{6} \mathrm{Da}$ is similar to guar gum and shows a polyelectrolyte behavior [5]. Sage seed gum adopts a self-structured rigid rod conformation in aqueous solution with more chain stiffness in comparison to xanthan gum. SSG dispersion demonstrates higher yield stress, pseudoplasticity, zero-shear 
viscosity and thermal stability compared with guar and xanthan gums [6]. According to described properties, SSG is an engrossing option to substitute commercial hydrocolloids in food, cosmetics, and pharmaceutical systems. However, most natural hydrocolloids present a weak network structure, so the preparation of high-strength SSG-based hydrogel for practical applications is challenging. Nanocomposite gel fabrication, using organic/inorganic nanoparticles (NPs) as reinforcing filler or cross-linker agent in a polymer matrix, is a new interesting strategy to overcome the shortcoming and developing novel hydrogels with tailorable and modified properties. Compared with the other attempts such as topological and double network gel production, which recently were made to design hydrogels with improved mechanical properties, the nanocomposite gel had the advantages of economy, stability, and simplicity of synthesis [7]. A key attribute of many bio-based nanohybrid hydrogels is their mechanical viscoelastic nature, which mimics hydrogel behavior as an intermediary commodity or final product. Besides, the formulation, ultimate characteristics, economic features of the process and shelf life of finished products are rheo-mechanical dependent factors [8]. Therefore tuning and characterizing hydrogel rheo-textural properties as a practical approach which supplies some useful evidence about nanoparticle dispersion pattern and matrix-particle interactions, are important when creating and maintaining engineered biomaterials. A number of studies on the linear and nonlinear viscoelastic (n-LVE) properties of renewable biopolymer-based (alginate, xanthan, locust bean gum, gelatin, scleroglucan and carboxymethyl cellulose) hydrogels, mainly for reinforced with NPs (silica montmorillonite, Laponite and zinc oxide), have been indicated that strong enhancements in the elasticity and stiffness of these systems occur with rising nanofiller contents. These changes often demonstrated by transitions from liquid-like to solid-like rheological behavior at relatively low NPs loadings with a high complex viscosity $\left(\eta^{*}\right)$ and complex modulus $\left(G^{*}\right)$ [9-15]. Titanium 
dioxide $\left(\mathrm{TiO}_{2}\right)$ is one of the best biocompatible and hydrophilic inorganic NPs, which is believed to be non-toxic, eco-friend and biosafe according to the Food and Drug Administration (FDA). Moreover, inexpensive nano- $\mathrm{TiO}_{2}$ possess antibacterial, odor inhibition and self-cleaning activity due to its photocatalytic mechanism [16]. The functional characteristics of nanocomposites were diverse and strongly governed by biopolymer and NPs nature, as well as their molecular size, shape, surface charge density, polymer-particle affinity, interactions, and ratio. The possibility of natural biopolymer- $\mathrm{TiO}_{2}$ interactions was approved by Fourier transform infrared (FT-IR) as mentioned in our previous works $[17,18]$. Large quantities of hydroxyl $(-\mathrm{OH})$ groups on nano$\mathrm{TiO}_{2}$ surface enable it to be functionalized/grafted with organic material and biopolymer chains. In addition, $\mathrm{TiO}_{2}$ has a strong affinity for carboxyl (-COOH) groups, and SSG chains have numerous carboxyl and hydroxyl agents, i.e., a lot of potential binding sites for $\mathrm{TiO}_{2}-\mathrm{NPs}$ surface. Furthermore, carboxylate groups on the repeating units of SSG chains can coordinate the Ti atoms on the nano- $\mathrm{TiO}_{2}$ in three different unidentate, chelating and bridge bidentate modes [19]. The presence of hydrogen bonding (H-bonding) as an important interaction in the $\mathrm{SSG}^{-\mathrm{TiO}_{2}}$ hybrid composite is expectable, which contributes to the improvement of mechanical properties. Such advantages make $\mathrm{TiO}_{2}$-NPs an ideal inorganic reinforcing component in manufacturing SSGbased nanohybrid hydrogel with novel promising functional properties and applications. In particular, $\mathrm{TiO}_{2}-\mathrm{NPs}$ were embedded into various forms of biopolymer matrix such as film, fluid and double-network gel [17-22]. However, most of these studies were related to the peruse of the antimicrobial activity, drug delivery, water vapor- and UV-shielding of nanocomposites and the investigations that examine the effect of nano- $\mathrm{TiO}_{2}$ on the physicochemical and viscoelastic properties of nanocomposite forming solution (NFS) and hydrogels have been very scarce. 
Nanocomposite (aerogel, tissue scaffold, and film) production using the casting/spreading technique consists of preparing the NFS followed by its molding and application onto a support, simply by pouring the NFS. Hence, it is seriously important to use an NFS with appropriate rheomechanical characteristics, which is obtained through an optimized matrix-filler ratio. In addition, the shelf-stability and functional features (adhesiveness and spreadability) of nanohybrid skin care creams and coating are textural-dependent properties. Thus, interested in developing SSG- $\mathrm{TiO}_{2}$ nanohybrid hydrogel, this work aimed to study the effect of nanoparticle concentrations $\left(\mathrm{C}_{\mathrm{NPs}}\right)$ on the rheo-mechanical and physicochemical attributes as well as understanding the microstructureproperty relations in $\mathrm{SSG}^{-\mathrm{TiO}_{2}} \mathrm{NFS}$ by means of small and large deformation tests, along physicochemical characterization.

\section{Materials and methods}

\subsection{Materials}

The extraction of SSG was accomplished using Bostan et al. [23] procedure. P25 titanium dioxide nanoparticles (80\% Anatase and 20\% Rutile) was supplied by Evonik Degussa GmbH (Germany). The average diameter, particle density and surface area of $\mathrm{TiO}_{2}$-NPs (as recorded by the company) were about $21 \mathrm{~nm}, 3.8 \mathrm{~g} / \mathrm{cm}^{3}$, and $50 \pm 15 \mathrm{~m}^{2} \cdot \mathrm{g}^{-1}$, respectively.

\subsection{Hydrogel preparation}

A series of nanocomposite hydrogels were produced by blending the $\mathrm{TiO}_{2}-\mathrm{NPs}$ with the SSG matrix as follows. A stock solution of nano- $\mathrm{TiO}_{2}(0.01 \mathrm{~g} / \mathrm{ml})$ was prepared by stirring overnight and sonication with $24 \mathrm{kHz}$ Hielscher UP200H ultrasound (Hielscher Ultrasonics, Germany) for 
two min at ambient temperature. $0,5,10,15,20$ and $25 \mathrm{ml}$ were taken from $\mathrm{TiO}_{2}$-NPs stock solution and added to the appropriate amount of de-ionized water until $99 \mathrm{ml}$ obtained with sodium azide $(0.02 \%)$ as an antimicrobial preservative. SSG (1 gr) was added very slowly to NPs dispersion under intense magnetic stirring (5 min, $700 \mathrm{rpm})$, at $25^{\circ} \mathrm{C}$. Instances were kept on rotating roller mixer (Haematology Cell Mixer, Iran) for further 24 hours at ambient temperature to complete hydration and also providing enough time to react with nanoparticles for any possible configurationally changes before the experiment.

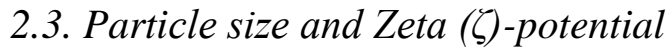

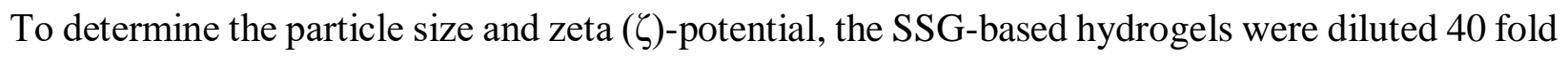
in de-ionized water and characterized in triplicate with a laser diffraction particle sizer (Cordouan, Vasco 3, and France) and dynamic light scattering (DLS) technique (ZetaCompact, CAD, and France), respectively at $25^{\circ} \mathrm{C}$.

\subsection{Density and Surface tension}

Density and surface tension of the nanocomposite samples were determined using Wilhelmy plate technique (K100, KRUSS, Germany) with a platinum-iridium plate (thickness: 0.2, width: 10 and length: $19.9 \mathrm{~mm}$ ) at $25^{\circ} \mathrm{C}$. All SSG-TiO 2 hydrogels were kept steady for $1 \mathrm{~h}$ to reach equilibrium before the measurements. De-ionized water was used for calibration of the instrument before to the analysis. Surface tension and density assessments were conducted, at least, in triplicate.

\subsection{Small amplitude oscillatory shear (SAOS) measurements}


Small deformation oscillatory measurements were performed using Physica MCR 301 controlled strain/stress rheometer (Anton Paar, GmbH, Germany) equipped with the cone-plate geometry $\left(4^{\circ}\right.$ angle, $0.206 \mathrm{~mm}$ gap and $50 \mathrm{~mm}$ diameter). The temperature was fixed at $20{ }^{\circ} \mathrm{C}$ using a Peltier system. Each sample was equilibrated, at least for two minutes before the rheological test and was coated around their periphery with light silicone oil to prevent water evaporation. The results of rheological measurements analyzed by Rheoplus software (Anton-Paar, version 3.21).

\subsubsection{Stress sweep test}

Stress sweep measurements in oscillatory shear were made over a stress range of $0.01-100 \mathrm{~Pa}$ in the controlled rate mode, at a constant temperature and frequency of $20^{\circ} \mathrm{C}$ and $1 \mathrm{~Hz}$, respectively, to determine the linear viscoelastic (LVE) region. In addition to detailed study on dynamic rheological characteristics of SSG and $\mathrm{SSG}-\mathrm{TiO}_{2}$ hydrogels, the elastic modulus $\left(\mathrm{G}_{\mathrm{LVE}}\right)$, viscous modulus $\left(\mathrm{G}_{\mathrm{LVE}}\right)$, complex modulus $\left(\mathrm{G}_{\mathrm{LVE}}^{*}\right)$, loss tangent $\left(\tan (\delta)_{\mathrm{LVE}}\right)$, the limiting value of stress ( $\tau_{d}$ or dynamic yield stress) at the LVE range, static yield stress $\left(\tau_{s}\right)$, flow-point stress $\left(\tau_{\mathrm{f}}\right)$ with corresponding modulus $\left(\mathrm{G}_{\mathrm{f}}\right.$ : $\left.\mathrm{G}^{\prime}=\mathrm{G}^{\prime \prime}\right)$, and the slope of the loss tangent at n-LVE range ofter flowpoint $\left(\tan (\delta)_{s(n-L V E)}\right)$ were calculated by the amplitude stress sweep test. Moreover, failure (fracture) stress $\left(\tau_{\mathrm{Fr}}\right)$ and failure strain $\left(\gamma_{\mathrm{Fr}}\right)$ were determined by plotting elastic stress, the product of the elastic modulus and strain amplitude $\left(\mathrm{G}^{\prime} \cdot \gamma\right)$, as a function of rising stress and strain, respectively [5].

\subsubsection{Frequency sweep test}

The frequency sweep experiments were carried out within the LVE region $(0.1 \mathrm{~Pa})$, over a frequency range of 0.01-10 Hz. The mechanical spectra were characterized by the elastic modulus 
$\left(G^{\prime}\right)$, viscous modulus $\left(G^{\prime \prime}\right)$, loss tangent $(\tan \delta)$, complex modulus $\left(G^{*}\right)$ and complex viscosity $\left(\eta^{*}\right)$, as a function of frequency. The frequency dependencies of $G^{\prime}$ and $G$ " for SSG-based hydrogels were described by a power law model using Eq. (1) and Eq. (2), respectively as follows:

$G^{\prime}=K^{\prime} \times(\omega)^{n^{\prime}}$

$G^{\prime \prime}=K^{\prime \prime} \times(\omega)^{n^{\prime \prime}}$

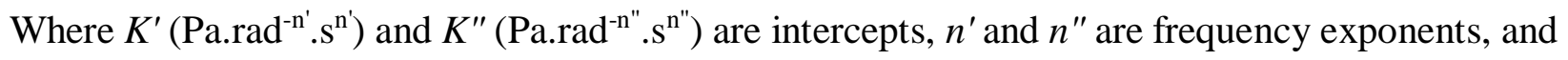

$\omega$ is the angular velocity $\left(\operatorname{rad} . \mathrm{s}^{-1}\right)$. Besides, the material stiffness parameter $\left(A_{\alpha}\left(\operatorname{Pa} \cdot \operatorname{rad}^{-\alpha} \cdot \mathrm{s}^{a}\right)\right)$ and the order of relaxation function ( $\alpha$ (dimensionless)) were determined by applying the Friedrich and Heymann [24] model (Eq. 3) on the complex modulus $\left(G^{*}\right)$ data:

$G^{*}=A_{\alpha} \times(\omega)^{\alpha}$

\subsection{Large deformation mechanical test}

Large deformation behavior of $\mathrm{SSG}_{-} \mathrm{TiO}_{2}$ hydrogels was investigated by the texture profile analysis (TPA) test, using a Brookfield Texture Analyzer (CT3, USA) according to a previously published method [25]. Experiments were carried out triplicate in a standard size back extrusion container disk (30 mm diameter; $45 \mathrm{~mm}$ length). The disk was proceeded at a rate of $1 \mathrm{~mm} / \mathrm{s}$ to penetrate twice into the gel to $40 \%$ degree of compression for the pre- and post-test (recovery time was zero) at ambient temperature. The slope of the linear region of the stress-strain curve was considered as the initial tangent modulus or apparent modulus of elasticity $\left(\mathrm{E}_{\mathrm{a}}(\mathrm{g} / \mathrm{s})\right)$. Other crucial parameters such as hardness (peak force during the initial compression cycle $(\mathrm{g})$ ), adhesiveness (negative force area of the initial cycle $(\mathrm{mJ})$ ), cohesiveness (ratio of the area under the second and first compression (dimensionless)), springiness (distance from the target deformation of primary 
cycle to the trigger point of second cycle $(\mathrm{cm})$ ), and gumminess (hardness $\times$ cohesiveness $(\mathrm{g}))$ of hydrogels were obtained.

\subsection{Statistical analysis}

All data were analyzed statistically based on a completely randomized factorial design using analysis of variance (ANOVA) procedure in SPSS software (Version19, Chicago, IL). The Duncan Duncan's Multiple-Region test was performed to determine the differences between mean values in case of significance $(\mathrm{P}<0.05)$.

\section{Results and discussion}

\subsection{Particle size}

Particle size measurement is a vital item in forecasting the rheological and electrophoretic behavior $\left(\zeta\right.$-potential) besides surface activity of the material. The average particle size of pure $\mathrm{TiO}_{2}$ and SSG were 21 and $277 \mathrm{~nm}$, respectively. As $C_{\mathrm{NPs}}$ increased to 5 and $10 \mathrm{wt} \%$, the particle size increased abruptly to 499 and $764 \mathrm{~nm}$, respectively (Table 1). The order of increasing particle size did not follow the order of NPs addition i.e., slowed down for high nano- $\mathrm{TiO}_{2}$ content. From zero to $25 \mathrm{wt} \%$ nano- $\mathrm{TiO}_{2}$, the composite size increased by about $264 \%$. At $\mathrm{C}_{\mathrm{NPs}}=5 \mathrm{wt} \%$, the particle size of SSG-5 $\mathrm{TiO}_{2}$ was 1.8-fold higher than that of plain SSG, but of the same order as the addition of $5 \mathrm{wt} \% \mathrm{TiO}_{2}$; at $\mathrm{SSG}-10 \mathrm{TiO}_{2}$ nanocomposite, the composite size was 1.5 -fold higher than SSG$5 \mathrm{TiO}_{2}$. Moreover, increasing of $\mathrm{TiO}_{2}$ contents from 10 to $20 \mathrm{wt} \%$ (double loading) led to the 1.2fold increment of particle size. The radius of gyration $\left(\mathrm{R}_{\mathrm{g}}\right)$ of rigid rod SSG molecule in an aqueous solution was found to be around 53-56 $\mathrm{nm}$ [26]. The average biopolymer rod diameter can 
approximately to be $2 R_{\mathrm{g}}=106-112 \mathrm{~nm}$. Thus, nano- $\mathrm{TiO}_{2}$ particle size $(21 \mathrm{~nm})$ is much smaller than polymer rod diameter value. This will cause a high bridging density even at the lowest NPs adding since individual SSG chains can physically connect to multiple $\mathrm{TiO}_{2}$. This condition beside powerful adsorption strength (H-bonding and $\mathrm{Ti}$ coordination) propelled to strong polymernanoparticle bridging interactions.

When NPs content increased, the number and size of $\mathrm{SSG}-\mathrm{TiO}_{2}$ flocculate and clusters increased, and the bridging interactions were strengthened. Hence, a 3D percolated matrix-NPs network was gradually developed. These microstructures play the most decisive role in the control of physicochemical and rheo-mechanical properties of nanocomposite hydrogels. These observations were in accordance with those obtained for gelatin- $\mathrm{TiO}_{2}$ [27], Poly(ethylene oxide)- $\mathrm{SiO}_{2}$ [28], xanthan- $\mathrm{ZnO}$ and xanthan- $\mathrm{CuO}$ [29] dispersions. In contrast, Oliveira et al. [13] indicated that increasing the amount of $\mathrm{SiO}_{2}-\mathrm{NPs}$ added to the locust bean gum (LBG) matrix increased the number of polymer-particle clusters, but not their average size.

Table 1

\subsection{Zeta (ל)-potential}

Zeta $(\zeta)$-potential reflects the effective charge of molecules in the dispersed system. The variation of $\zeta$-potential of nanocomposite material can be used as an indicator of the adsorption extent and electrostatic attraction/repulsion between polar or charged ion components. $\zeta$-potential is also a practical measurement for classification of stability of the multi-phase system via the DLVO (Derjagin-Landau-Verwey-Overbeek) surface steric force theory, which stated the more stable substance had higher $\zeta$-potential magnitudes (near to \pm 30 ) [30]. The $\zeta$-potential of $1 \%(w / w)$ nano- 
$\mathrm{TiO}_{2}$ and SSG solutions were approximate -12.7 and $-53.1 \mathrm{mV}$, respectively, at neutral $\mathrm{pH}$ (Table 1), showed a weak and strong negative charge on the surface of $\mathrm{TiO}_{2}-\mathrm{NPs}$ and $\mathrm{SSG}$ (anionic biomacromolecule), respectively. These values are expected, in accordance with the magnitudes in the literature [31,32] and suggested that $\mathrm{SSG}$ and $\mathrm{TiO}_{2}$ can act as an electron donor and acceptor, respectively [33]. As shown in Table 1, the addition of $\mathrm{TiO}_{2}$ in the low concentration (up to $5 \mathrm{wt} \%$ ) into the SSG colloidal gel did not affect the electrokinetic behavior of nanocomposite hydrogel. The possible reason for this finding might be that SSG is a long chain molecule when compared with the nanospheres of $\mathrm{TiO}_{2}$, especially at low contents. The $\mathrm{SSG}-\mathrm{TiO}_{2}$ flocculates were rapidly formed and the flocculates might be covered by SSG, resulting in an unaltered negatively charged surface of the flocculates, independent of the $\mathrm{TiO}_{2}$ concentration. The negative values of the $\zeta$ potential of SSG-based gel decreased significantly upon nano- $\mathrm{TiO}_{2}$ loading ( $\geq 10 \mathrm{wt} \%$ ), demonstrated that the dispersant NPs gradually covered and bound to the surface of the SSG macromolecules. However, in the case of SSG- $25 \mathrm{TiO}_{2}$, the $\zeta$-potential $(-39.7 \mathrm{mV})$ is higher than the minimum value $(-30 \mathrm{mV})$ which considered to a stable nanosuspension. The reduction of $\zeta$ potential in the presence of $\mathrm{TiO}_{2}$ at high concentration $(\geq 10 \mathrm{wt} \%$ ) and the lowest surface charge magnitude of the highest $\mathrm{TiO}_{2}$ fraction sample $\left(\mathrm{SSG}-25 \mathrm{TiO}_{2}\right)$ might be ascribed by the higher polymer-particle adsorption and interactions, created larger flocculated clusters having lower electrophoretic (electrokinetic) mobility with an increase in NPs fraction compared to small particles and flocculates, which can result in a decrease of $\zeta$-potential [34]. It should also be noted that the increment in particle size led to a decrease of the specific surface area of the particles. Considering the number of the charged groups on particle surface commensurate with the specific surface area, the increase in particle size could lead to a decline in the surface charge and the $\zeta$ - 
potential. This result was in good agreement with those reported for gelatin-nanoclay hydrogel [14].

\subsection{Density}

Density and its derivatives are essential intensive factors in fluid mechanics calculations and predicting the material thermodynamic properties and rheo-texture behavior. The density is directly proportional to the porosity (volume fraction, sizes, and their interconnection) of the hydrogel networks, which affected by composition and components interactions. Experimental values of SSG-based hydrogel density measurements shown in Table 1, presented with increasing $\mathrm{TiO}_{2}$ mass fraction (0-25 wt $\left.\%\right)$, the overall density of nanocomposite hydrogels shifted to higher values, as expected since the average density of the solid constituents of the $\mathrm{SSG}^{-\mathrm{TiO}_{2}}$ composite is higher than pure SSG density. The upward trend of the density indicated the specific volumetric shrinkage of the SSG-based hydrogel components upon $\mathrm{TiO}_{2}$ loading, which might be associated with the formation high-density inter and intramolecular agglomerate/aggregates microstructures due to the physicochemical interactions (H-bonding and chain entanglement) between the functional groups in SSG matrix and $\mathrm{TiO}_{2}$-NPs. Beside, polyelectrolytes coil dimensions in SSG may be shrunk by long-range electrostatic attractions [6]. Furthermore, positively charged $\mathrm{TiO}_{2}$ surface $\left(-\mathrm{Ti}^{4+}-\mathrm{O}\right)$ can form bridges between acid groups. Most of these bridges are intramolecular links, therefore lead to a further diminishing of the volume occupied by the hydrogel. It should also be noted that two different behaviors were seen depending on nano- $\mathrm{TiO}_{2}$ percentage. For $\mathrm{C}_{\mathrm{NPs}}$ $\leq 15 \mathrm{wt} \%$, density presented a slight dependence on solid content and increase from 1.47 in pure SSG to $1.50 \mathrm{~g} / \mathrm{ml}$ for $\mathrm{SSG}-15 \mathrm{TiO}_{2}$ was obtained, whereas for higher nanoparticle contents ( $>15$ wt $\%$ ), an abruptly increment in density with a very strong dependence on solid content could be 
noted. Apart from the obvious effect of shrinkage, the role of nano- $\mathrm{TiO}_{2}$ in increasing trend/order of density variations was not clear and no discussion has gone on it in the literature. However, similar results were observed for the swelling behavior of the polyacrylamide/alginate reinforced by different nanoparticles $\left(\mathrm{SiO}_{2}, \mathrm{Al}_{2} \mathrm{O}_{3}\right.$, and $\left.\mathrm{TiO}_{2}\right)$ [20] and carrageenan-silver [35] hydrogels due to the extra attractive force between polymer chains and NPs and decrease in porosity of the hydrogel networks.

\subsection{Surface tension}

Surface tension often plays a significant role in nanocomposite solution stability, its application as a delivery system or predicting the evaporation rate in film or aerogel preparation. When $\mathrm{TiO}_{2}$ was introduced to SSG gel, the surface energy of the gas-liquid interface gets affected because NPs induction changes at the molecular level through electrostatic interactions [36]. Surface tension decreased significantly at $5 \mathrm{wt} \%$ NPs in comparison with pure SSG (Table 1), demonstrated the presence of hydrophilic $\mathrm{TiO}_{2}$-NPs might pull more liquid molecules down from the interface, towards the particle floating in the interior and created a less dense region, so that reduced the free energy of the new interface in the $\mathrm{SSG}-5 \mathrm{TiO}_{2}$ nanohybrid hydrogel. This observation suggested that $\mathrm{TiO}_{2}-\mathrm{NPs}$ can act as a surface-active additive like as nano- $\mathrm{SiO}_{2}[37]$ at low levels $(\leq 5 \mathrm{wt} \%)$. A similar result was previously reported by Chinnam et al. [38] using different spherical metal oxide NPs $\left(\mathrm{TiO}_{2}, \mathrm{Al}_{2} \mathrm{O}_{3}\right.$, and $\left.\mathrm{SiO}_{2}\right)$ at concentrations below $6 \%(\mathrm{w} / \mathrm{w})$ in propylene glycol-water nanofluid. Surface tension of SSG-TiO 2 nanocomposite increased significantly $(64.0 \mathrm{mN} / \mathrm{m})$ until $\mathrm{C}_{\mathrm{NPs}}=10 \mathrm{wt} \%$ and reduced to $60.6-61.6 \mathrm{mN} / \mathrm{m}$ at $\mathrm{C}_{\mathrm{NPs}}=15-25 \mathrm{wt} \%$. It has been mentioned that enhance in surface tension and its irregular trend displayed at higher $\mathrm{C}_{\mathrm{NPs}}$ could be related to the high viscosity of $\mathrm{SSG}-\mathrm{TiO}_{2}$ composite hydrogel at higher NPs contents, which made interfacial 
measurement difficult by common techniques. In addition, the rise of the hydrogel density caused by the shrinkage presumably led to a settlement trend of the flocs, which affected the results of the surface tension measurement. This result was compatible with the results observed by Vafaei et al. [36] and Ranjbar et al. [39], which indicated that the surface tension of bismuth telluride $\left(\mathrm{Bi}_{2} \mathrm{Te}_{3}\right)$, Tri Ethylene Glycol- $\mathrm{Al}_{2} \mathrm{O}_{3}$ and $-\mathrm{MgO}$ nanofluid diminished to a minimum magnitude and then increased again with the loading of more NPs. They adjudged that this type of behavior in surface tension to be an outcome of charged NPs assembly and accumulation at the liquid-gas interface.

\subsection{Stress sweep}

Amplitude stress sweep test was conducted prior to performing the frequency sweep, to ensure operation within the LVE region and characterize the stress dependence of the viscoelastic response. According to the stress sweep outcomes, the frequency sweep assessments were carried out under the constant stress of $0.1 \mathrm{~Pa}$. Besides, the effects of $\mathrm{TiO}_{2}-\mathrm{NPs}$ on rheological behavior pattern and some related parameters from stress sweep presented in Fig. 1 and Table 2. In all SSGbased hydrogels with raising stress, two distinct regions were distinguished, (a) LVE region where $G^{\prime}$ and $G^{\prime \prime}$ were approximately steady and parallel with $G_{L V E}^{\prime}>G^{\prime \prime}{ }_{L E}$ (solid-like demeanor); and (b) n-LVE (nonlinear range) in which $\mathrm{G}^{\prime}$ and $\mathrm{G}^{\prime \prime}$ commenced to decrease. Generally, the magnitudes of $\mathrm{G}_{\mathrm{LVE}}$ and G" ${ }_{\mathrm{LVE}}$ of the SSG-based hydrogels increased significantly $(\mathrm{P}<0.05)$ upon $\mathrm{TiO}_{2}$ addition (5-25 wt $\%$ ), demonstrating the increase of system solidity (Table 2).

Figure 1

Table 2 
The increment in $\mathrm{G}_{\mathrm{LVE}}^{\prime}$ is marginal at low filler loading (up to $5 \mathrm{wt} \%$ ), slowly increases with augmenting $\mathrm{C}_{\mathrm{NPs}}$ and becomes noticeable above $15 \mathrm{wt} \%$. In contrast, the increment in $\mathrm{G}_{\mathrm{LVE}}$ of the nanocomposites due to the $\mathrm{TiO}_{2}$ addition was already substantial at $5 \mathrm{wt} \%$, which revealed that elastic and viscous elements were more affected by nano- $\mathrm{TiO}_{2}$ at high and low contents, respectively. $G_{\text {LVE }}^{*}$ which includes both viscoelastic moduli of a system showed an alike trend with G'LVE and illustrated that the total structural strength of SSG-based nanocomposite rose with NPs incorporation due the reinforcing effect of the inclusions (primary particles and clusters) [40]. $\operatorname{Tan}(\delta)_{\text {LVE }}$ was another assayed parameter which is defined as the ratio of loss to storage energy in the LVE range and stating the physical behavior of a system. All instances showed $0.1<\tan (\delta)_{\mathrm{LVE}}$ $>1$, demonstrated the predominance of G' which is the typical response of weak gels. Except at 5 $\mathrm{wt} \% \mathrm{TiO}_{2}, \tan (\delta)_{\mathrm{LVE}}$ of hydrogels decreased with the increase of $\mathrm{C}_{\mathrm{NPs}}$ (Table 2). Nanocomposite containing 5 and $25 \mathrm{wt} \% \mathrm{TiO}_{2}$ had highest and lowest $\tan (\delta)_{\mathrm{LVE}}$, respectively, which can be explained by the enhanced contribution of the viscous and elastic components at lower and higher $\mathrm{C}_{\mathrm{NPs}}$.

Dynamic yield stress $\left(\tau_{\mathrm{d}}\right)$ is defined as the limiting values of stress at the LVE range which caused the first non-linear microstructural changes. It depends on the molecular architecture in the matrixparticle structure and can be considered as the beginning point of the weakening of the gel strength. With the increase in $\mathrm{C}_{\mathrm{NPs}}$ from zero to $25 \mathrm{wt} \%$, the $\tau_{\mathrm{d}}$ significantly decreased from 4.45 to $1.45 \mathrm{~Pa}$ (Table 2). This phenomenon is usually attributable to the stress-induced disruption of the fragile structural interactions among the network building units. This kind of demeanor was observed for LBG- $\mathrm{SiO}_{2}$ solutions in the similar NPs concentration regime $(0-20 \mathrm{wt} \%)$ [13]. They ascribed this behavior to the low ionization of the $\mathrm{SiO}_{2}$-NPs or high ionic strength where the counter-ions can 
shield the charges on the $\mathrm{SiO}_{2}$ particles, especially for the systems with high $\mathrm{C}_{\mathrm{NPs}}$. Similar causes might apply for $\mathrm{SSG}^{-\mathrm{TiO}_{2}}$ hydrogels. Meanwhile, the shorter lasting structure of $\mathrm{SSG}^{-\mathrm{TiO}_{2}}$ than that of SSG alongside the stress axis may be due to the presence of powerful bonds in SSG-TiO 2 compared to pure SSG, which limited the chains mobility in the $\mathrm{SSG}^{-\mathrm{TiO}_{2}}$ hydrogel, hence, the time needed to form new interactions to replace those ruined by the external stress. On the contrary, static yield stress $\left(\tau_{\mathrm{s}}\right)$ of nanocomposite hydrogel increased significantly with the increase of $\mathrm{TiO}_{2}$ fraction, except for $5 \mathrm{wt} \%$ (Table 2). These different results with opposite trends in $\tau_{\mathrm{d}}$ and $\tau_{\mathrm{s}}$ indicated the existence of two different kinds of crosslinked or other interactive microstructure in the system. $T_{d}$ has demonstrated the value of stress for stopping a flowing test material (conversion from a viscoplastic to the solid behavior) which is related to more strong and insensitive construct to shear rate. On the other hand, the $\tau_{\mathrm{s}}$ is related to the shear-sensitive microstructure which formed over a definite period when the sample is at rest state, thus it is the magnitude of stress required to get the test material starts to flow (transformation from solid to viscoplastic state). Moreover, the $\tau_{\mathrm{s}}$ was greater than the $\tau_{\mathrm{d}}$ at each $\mathrm{C}_{\mathrm{NPs}}$ and the value of $\tau_{\mathrm{d}} / \tau_{\mathrm{s}}$ ratio decreased as $\mathrm{C}_{\mathrm{NPs}}$ increased because $\tau_{\mathrm{s}}$ is an outcome of the combined structure [5]. These results suggested that with an increase in $\mathrm{C}_{\mathrm{NPs}}$, the shear-sensitive $\left(\tau_{\mathrm{s}}\right)$ and shear-insensitive $\left(\tau_{\mathrm{d}}\right)$ microstructure extent in SSGbased hydrogel enhanced and reduced, respectively. The opposite trend of $\tau_{\mathrm{d}}$ with the viscoelastic moduli in the LVE range ( $G_{L V E}^{\prime}$ and $\left.G^{\prime \prime}{ }_{L V E}\right)$ suggested the formation of a more strong but fragile 3D temporary network microstructure upon $\mathrm{C}_{\mathrm{NPs}}$ loading and supported the idea that interfacial slippage occurred in the higher filler composites. For all hydrogels, beyond the critical stress amplitude, the LVE range was utterly left and $G^{\prime}$ can cross $G^{\prime \prime}\left(G^{\prime}=G^{\prime \prime}\right)$ (Fig. 1). At this point, the material collapses and the gel structure is irreversibly altered. The stress at crossover/flow point $\left(\tau_{\mathrm{f}}\right)$ which illustrates the stress of viscoelastic to elastoviscous state transformation, considered as 
a good indicator of resistance to flow. $\mathrm{T}_{\mathrm{f}}$ for SSG-based hydrogels decreased as $\mathrm{C}_{\mathrm{NPs}}$ increased up to $5 \mathrm{wt} \%$ but thereafter gained to the highest amount of $19.40 \mathrm{~Pa}$ at $20 \mathrm{wt} \%$, showing slight inclination to flow of SSG-20TiO 2 nanocomposite (Table 2). At the flow point, viscoelastic moduli diminished rapidly, thus the corresponding modulus $\left(\mathrm{G}_{\mathrm{f}}\right)$ indicates the system stiffness and behavior changes. $\mathrm{G}_{\mathrm{f}}$ increased significantly from 13.64 to $15.21 \mathrm{~Pa}$ as a function of $\mathrm{C}_{\mathrm{NPs}}(0-15$ $\mathrm{wt} \%)$ and remain constant at high $\mathrm{C}_{\mathrm{NPs}}(\geq 15 \mathrm{wt} \%)$, presented that the matrix-filler associations prevailed the effect of deformation force.

As the applied stress was increased, the gel body failure led to a sharp reduction in the G' and G" magnitudes. Failure strain or stress was distinguished as the strain/stress at which macroscopic rupture arise in the system. Failure properties are usually regarded as indicators of structural arrangement and an important part of a comprehensive evaluation of gel stability and load-bearing applications. Failure stress $\left(\tau_{\mathrm{Fr}}\right)$ of plain SSG and SSG-15TiO 2 are shown in Fig. 2. SSG-based hydrogels exhibited characteristic increases in $\gamma_{\mathrm{Fr}}$ with $\mathrm{C}_{\mathrm{NPs}}$ as follows. In the low $\mathrm{C}_{\mathrm{NPs}}$ region (up to $5 \mathrm{wt} \%), \gamma_{\mathrm{Fr}}$ and $\tau_{\mathrm{Fr}}$ changed insignificantly. The early failure of hydrogels is reasonably due to the laxity of the gel systems, made them incapable to tolerate large external forces. Besides, a matrix carrying the highest stress, normally the shortest and weakest one in extension and linkage, respectively, failed first. Between 5 and $15 \mathrm{wt} \% \mathrm{TiO}_{2}, \gamma_{\mathrm{Fr}}$ and $\tau_{\mathrm{Fr}}$ increased more rapidly with increasing $\mathrm{C}_{\mathrm{NPs}}$, and finally from 15 to $25 \mathrm{wt} \%$, the value of $\gamma_{\mathrm{Fr}}$ and $\tau_{\mathrm{Fr}}$ decreased considerably, but they were still much greater than that of the pure SSG hydrogel (Table 2). The precipitous increase in the range of 5-15 $\mathrm{wt} \% \mathrm{TiO}_{2}$ may be related to the formation of the rigid microstructure. The reason for $\gamma_{\mathrm{Fr}}$ and $\tau_{\mathrm{Fr}}$ reduction for $\mathrm{C}_{\mathrm{NPs}}$ above $15 \mathrm{wt} \%$ is the increased brittleness, probably due to the presence of large-scale aggregated excessive $\mathrm{TiO}_{2}$-NPs in the gel matrix, which could diminish the structural integrity of hydrogel and its persistence versus crack initiation, propagation, 
and failure [41]. These results are in line with previous findings that addition of hectorite and $\mathrm{SiO}_{2}$ NPs improves fractural properties of the polyacrylamide derivatives hydrogel/hybrid materials $[42,43]$.

Figure 2

Spreadability is a crucial subjective textural attribute of semisolid and elastoplastic biomaterial which could be shown as index of ease and uniform casting process (in film, aerogel, and tissue engineered scaffold fabrication), coating and therapy applications (wound healing, skin care, and topical creams). The higher value of $\tan (\delta)_{\mathrm{s}(\mathrm{n}-\mathrm{LVE})}$ which illustrates the viscous/elastic components behaviors changes with stress at the n-LVE range, could be considered as an indicator of higher spreadability index $(\mathrm{SI})$ of a system. The $\tan (\delta)_{\mathrm{s}(\mathrm{n}-\mathrm{LVE})}$ values became steeper (higher SI) by incorporation of $\mathrm{TiO}_{2}$-NPs in the semisolid SSG matrix and reached a maximum of 2.03 for SSG$20 \mathrm{TiO}_{2}$ sample (Table 2). This might be related to the decrease of SSG polymer mass fraction from 1 in pure SSG gel to 0.83 in $\mathrm{SSG}-20 \mathrm{TiO}_{2}$ nanocomposite hydrogel. It is important to note that the SI gave similar trend with gumminess and inverse trend to the cohesiveness and dynamic yield stress.

\subsection{Frequency sweep}

Typical frequency $(\omega)$ dependence linear viscoelasticity of pure SSG and SSG-20TiO 2 over the range of $0.1-10 \mathrm{~Hz}$ at a fixed stress and temperature $\left(0.1 \mathrm{~Pa}, 20^{\circ} \mathrm{C}\right)$ was shown in Fig. 3 , respectively. In all SSG-based nanocomposite, the value of $\mathrm{G}^{\prime}$ was almost independent of $\omega$ (plateau-like), higher than that of $\mathrm{G}^{\prime \prime}(\omega)$ and without any cross point in the applied frequency, suggested the SSG-based systems were viscoelastic solid-like hydrogels. 
Figure 3

The variation in $\mathrm{G}_{1 \mathrm{~Hz}}^{\prime}, \mathrm{G}^{\prime \prime}{ }_{1 \mathrm{~Hz}}, \mathrm{G}^{*}{ }_{1 \mathrm{~Hz}}, \eta^{*}{ }_{1 \mathrm{~Hz}}$ and $\tan \delta_{1 \mathrm{~Hz}}$ of SSG-based hydrogels were presented in Table 3 as a function of $\mathrm{TiO}_{2}-\mathrm{NPs}$ concentration. It can be seen that increasing $\mathrm{C}_{\mathrm{NPs}}$ from 5 to 20 wt\% caused a prominent increase, from 34.9 to $59.1 \mathrm{~Pa}$ in $\mathrm{G}_{1 \mathrm{~Hz}}^{\prime}$ of instances. Elastic behavior is related to the number of cross-links and bridges in the material [41] thus the higher $\mathrm{G}_{1}^{\prime} \mathrm{Hz}$ magnitude was associated with tougher hydrogel $\left(\mathrm{SSG}-20 \mathrm{TiO}_{2}\right)$, which were in accordance with stress sweep findings (Table 2). However, the results demonstrated clearly that further addition of $\mathrm{TiO}_{2}$ (up to $25 \mathrm{wt} \%$ ) decreased $\mathrm{G}_{1 \mathrm{~Hz}}^{\prime}$ to $51.3 \mathrm{~Pa}$, illustrated softening of the hydrogels due to the incorporation of exceeded NPs.

Similar observations were recently reported on the effect of nano- $\mathrm{TiO}_{2}$ in collagen or collagen/chitosan [41], poly(vinyl alcohol) [44] and chitin [45] hydrogels. They have found that above a certain NPs concentration, the rheo-mechanical properties of a polymer- $\mathrm{TiO}_{2}$ hybrid have remarkably declined due to the existence of the coarser particles resulting from the aggregation of originally introduced nano- $\mathrm{TiO}_{2}$. Presumably, a similar mechanism of $\mathrm{TiO}_{2}-\mathrm{NPs}$ disjunction from the SSG matrix and creation of numerous loosened clusters which prevent the cross-linking process, resulting in worsening of rheological properties operated in these systems. Tan $\delta_{1 \mathrm{~Hz}}$ of SSG-based hydrogels was in the range of $0.42-0.54$, which indicated their weak biopolymer hydrogel construct. $\mathrm{G}^{\prime \prime}{ }_{1 \mathrm{~Hz}}, \mathrm{G}^{*}{ }_{1 \mathrm{~Hz}}$, and $\eta^{*}{ }_{1 \mathrm{~Hz}}$ showed a similar trend with $\mathrm{G}_{1 \mathrm{~Hz}}$ at any SSG-TiO 2 ratio (Table 3). As $\mathrm{C}_{\mathrm{NPs}}$ increased, $\eta^{*}{ }_{1 \mathrm{~Hz}}$ enhanced considerably, reflected that $\mathrm{TiO}_{2}$ enhanced the strength of the biopolymeric matrix, probably as the NPs mediate chain interactions fabricated sizable domains of aggregated/self-associated SSG (refer to section 3.1). However, upon $25 \mathrm{wt} \%$ 
$\mathrm{TiO}_{2}$ loading, $\eta^{*}{ }_{1 \mathrm{~Hz}}$ decreased significantly, illustrated the high viscosity of the nanocomposite hydrogels was not a direct outcome of the particles size but was contributed to the strong propensity of particles to create clusters [40].

Figure 4

Complex viscosity $\left(\eta^{*}\right)$ decreased almost linearly with the increment of frequency in all hydrogels

(Fig. 4) revealed non-Newtonian shear-thinning behavior (pseudoplastic nature) of SSG-based hydrogels which revealed the presence of interlacing molecular interactions in the system. Shearthinning demeanor may be due to the formation of the shear-induced alignment of the $\mathrm{SSG}^{-\mathrm{TiO}_{2}}$ segments towards the flow direction. Besides, at high frequency the period time is not adequate to rebuild broken intra- and intermolecular linkage, disentanglement or molecular alignment of longchain polymers, and subsequently, the downtrend in $\eta^{*}$ occurred [5]. The slope of the $\eta^{*}$-frequency curves $\left(\eta^{*}\right.$ s) of pure SSG was -0.82 . It increased after $\mathrm{TiO}_{2}$ loading, approved that the elasticity of the samples was positively affected by the addition of $\mathrm{TiO}_{2}$-NPs. $\eta^{*}$ s of SSG-based hydrogels in the range from -0.80 to -0.89 , which were remarkably higher than the highest magnitude of -0.76 which considered for weak polysaccharide gel, formed by overlapping and entangled flexible random coil chains.

Table 3

Table 4

Power law model (Eqs. (1), (2) and (3)) delineated adequately the frequency dependence of the G', 
$G^{\prime \prime}$ and $G^{*}$ moduli for all SSG-based instances. It was found that all hydrogels exhibited solid-like elastic behavior because the slopes $\left(n^{\prime}=0.11-0.28\right.$ and $\left.n^{\prime \prime}=0.26-0.58\right)$ were much lower than values suggested for a simple Maxwellian system $\left(\mathrm{G}^{\prime} \infty \omega^{2}\right.$ and $\left.\mathrm{G}^{\prime \prime} \infty \omega\right)$, and $K^{\prime}$ magnitudes much larger than those of $K^{\prime \prime}$. In addition, $n^{\prime}$ and $n^{\prime \prime}$ values (frequency dependence) decreased and $K^{\prime}$ and $K^{\prime \prime}$ increased with the rise in $\mathrm{C}_{\mathrm{NPs}}$ (up to $20 \mathrm{wt} \%$ ), pointed out that the polymer relaxation, chain reputation, and 3D network became slower, more restrained and stronger, respectively (Table 4). With further increment in $\mathrm{TiO}_{2}$ to $25 \mathrm{wt} \%$, the rigidity of continuous phase deteriorated (enhancement of $n^{\prime}$ and $n^{\prime \prime}$ and reduction of $K^{\prime}$ values). Since the simply reinforcing effect would give an increase in viscoelastic moduli without a change in the frequency dependence $\left(n^{\prime}\right.$ and $\left.n^{\prime \prime}\right)$, obtained results illustrated a structural modification of the nanocomposites with the $\mathrm{TiO}_{2}$ load [46]. The strength and the number of conceivable interactions in the $\mathrm{SSG}-\mathrm{TiO}_{2} 3 \mathrm{D}$ network were specified by using the material stiffness parameter $\left(A_{\alpha}\right)$ and the order of relaxation function $(\alpha)$ (Table 4). With increasing $\mathrm{TiO}_{2}$ fraction, the values of $A_{\alpha}$ raised except for $\mathrm{SSG}-25 \mathrm{TiO}_{2}$ which showed lower stiffness than $\mathrm{SSG}-20 \mathrm{TiO}_{2}$ indicated the increase in the polymer-polymer and polymer-particle bridging or cross-linking (network strength) with $\mathrm{C}_{\mathrm{NPs}}$. The origin of enhancing in stiffness might be pertinent to the creation of large-scale microstructures, heterogeneities and possibly compacted $\mathrm{SSG}-\mathrm{TiO}_{2}$ segments that act as elastic springs to augment the $3 \mathrm{D}$ network structure. In addition, $\alpha$ abated with $\mathrm{C}_{\mathrm{NPs}}$ increment. Lower magnitude of $\alpha$ related to a higher number of interactions, greater network extension and shear thinning behavior in SAOS [5].

\subsection{Large deformation properties}

Most of the practical application features of hydrogels, such as handling, shaping and casting (for scaffold tissue, film and aerogel fabrication) are closely related to the large deformation and 
fracture characteristics of gels. Therefore, the internal network properties of SSG-based hydrogels and reinforcement effect of nano- $\mathrm{TiO}_{2}$ at large deformation values were studied with the texture profile analysis (TPA) test. The important textural properties were determined from the resultant force-time curves (Table 5). All hydrogels indicated a rapid non-linear increase in the force over a short time as the probe propelled into the samples, even though the initial slope was dissimilar for different hydrogels (data not shown), demonstrated the formation of elastic and stiff systems relying on the $\mathrm{SSG}^{-\mathrm{TiO}_{2}}$ ratio. In addition, the non-linear correlation of force and corresponding deformation supported the non-Gaussian nature of the SSG-based network distribution over the whole range of deflection, manifested in a non-linear relationship between force and distance of polymer crosslinks and bridges connections. With an increase in $\mathrm{C}_{\mathrm{NPs}}$ from zero to $15 \mathrm{wt} \%$, the hardness increased prominently from $255 \mathrm{~g}$ to $325 \mathrm{~g}$. Nevertheless, incorporation of more $\mathrm{TiO}_{2}$ NPs up to $20 \mathrm{wt} \%$ led to a slight reduction in hardness (307 g) and afterward, it sharply decreased to the lowest value of $246 \mathrm{~g}$ in $\mathrm{SSG}-25 \mathrm{TiO}_{2}$. An increment in hardness of $\mathrm{SSG}^{-\mathrm{TiO}_{2}}$ hydrogels might be exhibited the creation of clusters of ordered microstructure along the polysaccharide chains upon $\mathrm{TiO}_{2}$ addition, which subsequently led to aggregation of these junction zones and formation a more rigid and compact 3D percolated network. Such observations were similarly made in the tamarind seed gum-nanofibrillated cellulose [3] and alginate [47,48] hydrogels. They ascribed this behavior by strain-stiffening (-hardening) effect which is a rather general phenomenon for biopolymeric-based gel [49]. Several possible scenarios such as high stretchability and loose consistency [3], deformation of rod-like junction zone [47], structure densification and highly crosslinked polymer systems [48] have been proposed to explain the strain-stiffening phenomenon. According to aforementioned observations, strain-stiffening became more notable as $\mathrm{C}_{\mathrm{NPs}}$ increased up to $15 \mathrm{wt} \%$, but thereafter it diminished. The relative 
and abruptly decrease in hardness and strain-stiffening at $\mathrm{C}_{\mathrm{NPs}}=20$ and $25 \mathrm{wt} \%$, respectively, presumably be attributed to the heterogeneous microstructure resulting from more aggregation of $\mathrm{TiO}_{2}$, as mentioned earlier.

Table 5

Cohesiveness is an index of internal structure strength and its resistance to breaking down. When the $\mathrm{C}_{\mathrm{NPs}}$ increased from 0 to $15 \mathrm{wt} \%$, the cohesiveness value decreased from 0.68 to 0.56 , probably due to the inhomogeneous embedding of $\mathrm{TiO}_{2}-\mathrm{NPs}$, and consequently partially phase separation in the system. On the other hand, when $\mathrm{C}_{\mathrm{NPs}}$ increased to $25 \mathrm{wt} \%$, cohesiveness rose and attained 0.62 (Table 5). This behavior was also observed in gelatin- [50], guar- and tamarind seed gumnanofiber cellulose [3] hydrogels and pointed out that the internal structure of nanocomposite gel became more brittle (facile to break) by the initial compression, with increasing $\mathrm{C}_{\mathrm{NPs}}$. The adhesiveness is an interfacial property which demonstrates the force of holding dissimilar particles/surfaces together for extended periods of time. Adhesion characteristics can undoubtedly have a significant impact on energy consumption in fluid transportation and cooling/heating process of operations via boundary layer effect. The extent of adhesion depends on various factors including the size, flexibility, conformation and other physicochemical properties of the polymer and the environment in which it resided in. Adhesive strength has been shown a positive correlation with polymer molecular weight and its solution viscosity [51]. As $\mathrm{C}_{\mathrm{NPs}}$ increased up to 5 wt\%, adhesion energy reduced, on the contrary, samples with higher $\mathrm{C}_{\mathrm{NPs}}(10-15 \mathrm{wt} \%)$ had a more significant trend of hydrogel adhesion (stickiness) on the surface. Adhesiveness decreased with the increased loading of $\mathrm{TiO}_{2}$ content (20 and $25 \mathrm{wt} \%$ ) into the SSG matrix, might be due to high 
cohesive bond strength in these hydrogels that prevents the formation of adhesive interactions [52]. These results were in accordance with that reported for poly(ethylene glycol) $-\mathrm{SiO}_{2}$ nanocomposite hydrogel stickiness [53] and demonstrated that the formation and strength of adhesive interactions were mainly governed by NPs filling, composition and network homo-heterogeneity of the hydrogel matrix. Six general theories have been adapted to describe the fundamental mechanisms involved in biological macromolecules stickiness [54]. We believe that the fracture theory which assumed that the failure of the adhesive bond occurs at the weakest interface is appropriately explained the detachment force in the semi-rigid SSG-based hydrogel. In this theory, the adhesive strength and work of failure have a direct relation with Young's modulus of elasticity and molecular weight of the network strands, respectively [55].

Springiness which sometimes referred as gel elastic recovery or rubberiness shows the physically springs back of a sample after the first compression. Gumminess is the denseness that persists throughout deformation or the energy required to disintegrate a semi-solid material and used to describe its viscous properties [56]. Similar to other textural characteristics, two different behaviors were observed depending on $\mathrm{TiO}_{2}$ concentration (Table 5). For $\mathrm{C}_{\mathrm{NPs}} \leq 10 \mathrm{wt} \%$, an increase of springiness and gumminess could be noted, whereas for $\mathrm{C}_{\mathrm{NPs}}>10 \mathrm{wt} \%$, a diminution in these factors was acquired. This observation reflected that at low $\mathrm{C}_{\mathrm{NPs}}(\leq 10 \mathrm{wt} \%)$, the structure of SSG- $\mathrm{TiO}_{2}$ gel was broken into few massive pieces during the first TPA compression whilst at $\mathrm{C}_{\mathrm{NPs}}>10 \mathrm{wt} \%$, less springy texture resulted from the hydrogel breaking into many small pieces [57]. The initial tangent modulus or apparent modulus of elasticity $\left(\mathrm{E}_{\mathrm{a}}\right)$ is a measure of the degree of the material stiffness at low deformation level. As expected, with increasing $\mathrm{C}_{\mathrm{NPs}}$ from 0 to 15 and $25 \mathrm{wt} \%$, the values of $\mathrm{E}_{\mathrm{a}}$ first increased from 106.4 to $177.6 \mathrm{~g} / \mathrm{s}$, and then decreased to 103.9 $\mathrm{g} / \mathrm{s}\left(\mathrm{SSG}-25 \mathrm{TiO}_{2}\right)$, revealed that $\mathrm{TiO}_{2}-\mathrm{NPs}$ act as physical crosslinking reagents [58] and created 
a stiffer microstructure at low $\mathrm{TiO}_{2}$ levels $(\leq 15 \mathrm{wt} \%)$. The $\mathrm{E}_{\mathrm{a}}$ reduction with higher $\mathrm{C}_{\mathrm{NPs}}$ can be attributed to the degradation of the integrity of the hydrogels network structure as discussed earlier.

\section{Conclusions}

In this study, the physicochemical and rheo-mechanical characteristics of new environmental friendly $\mathrm{TiO}_{2}$-reinforced, SSG-based hydrogels were investigated. Incorporation of $\mathrm{TiO}_{2}-\mathrm{NPs}$ significantly decreased the zeta potential, and enhanced density and particle size of SSG-TiO 2 hydrogels besides, severely changed their surface tension. Local secondary microstructure (soft flocks and hard clusters) formation and percolated 3D network, depending on their number and strength (as a consequence of the chain entanglement, polymer-particle, and interparticle possibly interactions), lead to gel structural modification evidenced by a gradual increase in viscoelastic moduli and decrease in their frequency dependency. Non-linear viscoelastic region data indicated the incorporation of nano- $\mathrm{TiO}_{2}$ increased the spreadability index of NFS, which is a favor in skin care creams and coating substances. Large deformation mechanical analysis also confirmed that the addition of $\mathrm{TiO}_{2}-\mathrm{NPs}$ up to a critical level (15 wt $\%$ ) caused hydrogels to be more hard, adhesive, springy and less cohesive. However, these incremental effects diminished with the NPs load beyond $15 \mathrm{wt} \%$. The knowledge of the rheo-mechanical characteristics of hydrogels systems is crucial to handle the NFS casting/application on support or use as spreadable biomaterials. Taking into account all data demonstrated, it can be declared that developed SSG-15TiO 2 nanohybrid hydrogel is a promising candidate for bio-based composites applications where the tunable textural features and augmented structures are favorable. 


\section{References}

[1] K. Haraguchi, H. Li, Mechanical properties and structure of polymer-clay nanocomposite gels with high clay content, Macromolecules. 39 (2006) 1898-1905.

[2] F. Ullah, M.B.H. Othman, F. Javed, Z. Ahmad, H.M. Akil, Classification, processing and application of hydrogels: A review, Mater. Sci. Eng. C. 57 (2015) 414-433.

[3] A. Ghafar, K. Parikka, T. Sontag-Strohm, M. Österberg, M. Tenkanen, K.S. Mikkonen, Strengthening effect of nanofibrillated cellulose is dependent on enzymatically oxidized polysaccharide gel matrices, Eur. Polym. J. 71 (2015) 171-184.

[4] T. dos Santos, R. Hernández, N. Rescignano, L. Boff, H. Reginatto, C. Simões, A. de Campos, C. Mijangos, Nanocomposite chitosan hydrogels based on PLGA nanoparticles as potential biomedical materials, Eur. Polym. J. 99 (2018) 456-463.

[5] S.M.A. Razavi, A. Alghooneh, F. Behrouzian, Influence of temperature on sage seed gum (Salvia macrosiphon) rheology in dilute and concentrated regimes, J. Dispers. Sci. Technol. (2017) $1-14$.

[6] F. Behrouzian, S.M.A. Razavi, A. Alghooneh, Evaluation of interactions of biopolymers using dynamic rheological measurements: Effect of temperature and blend ratios, J. Appl. Polym. Sci. 134 (2017).

[7] P. Li, N.H. Kim, D. Hui, K.Y. Rhee, J.H. Lee, Improved mechanical and swelling behavior of the composite hydrogels prepared by ionic monomer and acid-activated Laponite, Appl. Clay Sci. 46 (2009) 414-417.

[8] S. Ahmadzadeh, A. Nasirpour, J. Keramat, S. Desobry, Effect of surface-modified montmorillonite on viscosity and gelation behavior of cellulose/ $\mathrm{NaOH}$ solution, Cellulose. 
22 (2015) 1829-1839.

[9] Z. Zare-Akbari, H. Farhadnejad, B. Furughi-Nia, S. Abedin, M. Yadollahi, M. KhorsandGhayeni, PH-sensitive bionanocomposite hydrogel beads based on carboxymethyl cellulose/ZnO nanoparticle as drug carrier, Int. J. Biol. Macromol. 93 (2016) 1317-1327.

[10] S.A. Oleyaei, S.M.A. Razavi, K.S. Mikkonen, Novel nanobiocomposite hydrogels based on sage seed gum-Laponite: Physico-chemical and rheological characterization, Carbohydr. Polym. 192 (2018) 282-290.

[11] R. Lapasin, M. Abrami, M. Grassi, U. Sebenik, U. Šebenik, Rheology of Laponitescleroglucan hydrogels, Carbohydr. Polym. 168 (2017) 290-300.

[12] J.L. Dávila, M.A. d'Ávila, Laponite as a rheology modifier of alginate solutions: Physical gelation and aging evolution, Carbohydr. Polym. 157 (2017) 1-8.

[13] F. Oliveira, S.R. Monteiro, A. Barros-Timmons, J.A. Lopes-da-Silva, Weak-gel formation in dispersions of silica particles in a matrix of a non-ionic polysaccharide: Structure and rheological characterization, Carbohydr. Polym. 82 (2010) 1219-1227.

[14] F. Karimi, N. Taheri, R. Namivandi, Fish gelatin/Laponite biohybrid elastic coacervates: A complexation kinetics-structure relationship study, Int. J. Biol. Macromol. 61 (2013) 102113.

[15] J.R.M. Kennedy, K.E. Kent, J.R. Brown, Rheology of dispersions of xanthan gum, locust bean gum and mixed biopolymer gel with silicon dioxide nanoparticles, Mater. Sci. Eng. C. 48 (2015) 347-353.

[16] B. Ghanbarzadeh, S.A. Oleyaei, H. Almasi, Nanostructured Materials Utilized in Biopolymer-based Plastics for Food Packaging Applications, Crit. Rev. Food Sci. Nutr. 55 (2015) 1699-1723. 
[17] S.A. Oleyaei, H. Almasi, B. Ghanbarzadeh, A.A. Moayedi, Synergistic reinforcing effect of $\mathrm{TiO}_{2}$ and montmorillonite on potato starch nanocomposite films: Thermal, mechanical and barrier properties, Carbohydr. Polym. 152 (2016) 253-262.

[18] S.A. Oleyaei, Y. Zahedi, B. Ghanbarzadeh, A.A. Moayedi, Modification of physicochemical and thermal properties of starch films by incorporation of $\mathrm{TiO}_{2}$ nanoparticles, Int. J. Biol. Macromol. 89 (2016) 256-264.

[19] M. Nešić, J. Žakula, L. Korićanac, M. Stepić, M. Radoičić, I. Popović, Z. Šaponjić, M. Petković, Light controlled metallo-drug delivery system based on the $\mathrm{TiO}_{2}$-nanoparticles and Ru-complex, J. Photochem. Photobiol. A Chem. 347 (2017) 55-66.

[20] Y. Zhai, H. Duan, X. Meng, K. Cai, Y. Liu, L. Lucia, Reinforcement effects of inorganic nanoparticles for double-network hydrogels, Macromol. Mater. Eng. 300 (2015) 12901299.

[21] R. Shu, Y. Gan, H. Lv, D. Tan, Preparation and rheological behavior of ethylene glycolbased TiO2 nanofluids, Colloids Surfaces A Physicochem. Eng. Asp. 509 (2016) 86-90.

[22] A. Shakouri, H. Ahmadi, M. Hojjat, S. Zeinali, Effect of $\mathrm{TiO}_{2}$ Nanoparticle on Rheological Behavior of Poly(vinyl alcohol) Solution, J. Vinyl Addit. Technol. 23 (2017) 234-240.

[23] A. Bostan, S. Razavi, R. Farhoosh, Optimization of hydrocolloid extraction from wild sage seed (Salvia macrosiphon) using response surface, Int. J. Food Prop. 13 (2010) 1380-1392.

[24] C. Friedrich, L. Heymann, Extension of a model for crosslinking polymer at the gel point, J. Rheol. 32 (1988) 235-241.

[25] S. Naji, S.M.A. Razavi, Functional and textural characteristics of cress seed (Lepidium sativum) gum and xanthan gum: Effect of refrigeration condition, Food Biosci. 5 (2014) 18. 
[26] S.M.A. Razavi, S.W. Cui, Q. Guo, H. Ding, Some physicochemical properties of sage (Salvia macrosiphon) seed gum, Food Hydrocoll. 35 (2014) 453-462.

[27] Q. He, Y. Zhang, X. Cai, S. Wang, Fabrication of gelatin- $\mathrm{TiO}_{2}$ nanocomposite film and its structural, antibacterial and physical properties, Int. J. Biol. Macromol. 84 (2016) 153-160.

[28] Q. Zhang, L.A. Archer, Optical polarimetry and mechanical rheometry of poly (ethylene oxide)-silica dispersions, Macromolecules. 37 (2004) 1928-1936.

[29] S. Ponmani, J. Karen, M. William, R. Samuel, R. Nagarajan, J.S. Sangwai, Colloids and Surfaces A: Physicochemical and engineering aspects formation and characterization of thermal and electrical properties of $\mathrm{CuO}$ and $\mathrm{ZnO}$ nanofluids in xanthan gum, Colloids Surface A Physicochem. Eng. Asp. 443 (2014) 37-43.

[30] T. Coviello, A.M. Trotta, C. Marianecci, M. Carafa, L. Di Marzio, F. Rinaldi, C. Di Meo, F. Alhaique, P. Matricardi, Gel-embedded niosomes: Preparation, characterization and release studies of a new system for topical drug delivery, Colloids Surfaces B Biointerfaces. 125 (2015) 291-299.

[31] H. Mohammadzadeh, A. Koocheki, R. Kadkhodaee, S.M.A. Razavi, Physical and flow properties of d-limonene-in-water emulsions stabilized with whey protein concentrate and wild sage (Salvia macrosiphon) seed gum, Food Res. Int. 53 (2013) 312-318.

[32] M. Hashimoto, H. Takadama, M. Mizuno, T. Kokubo, Mechanical properties and apatite forming ability of $\mathrm{TiO}_{2}$ nanoparticles/high density polyethylene composite: Effect of filler content, J. Mater. Sci. Mater. Med. 18 (2007) 661-668.

[33] J.J. Zhou, S.Y. Wang, S. Gunasekaran, Preparation and characterization of whey protein film incorporated with $\mathrm{TiO}_{2}$ nanoparticles, J. Food Sci. 74 (2009) 50-56.

[34] J. Wang, G. Liu, L. Wang, C. Li, J. Xu, D. Sun, Synergistic stabilization of emulsions by 
poly(oxypropylene)diamine and Laponite particles, Colloids Surfaces A Physicochem. Eng. Asp. 353 (2010) 117-124.

[35] S. Azizi, R. Mohamad, R. Abdul Rahim, R. Mohammadinejad, A. Bin Ariff, Hydrogel beads bio-nanocomposite based on Kappa-carrageenan and green synthesized silver nanoparticles for biomedical applications, Int. J. Biol. Macromol. 104 (2017) 423-431.

[36] S. Vafaei, A. Purkayastha, A. Jain, G. Ramanath, T. Borca-Tasciuc, The effect of nanoparticles on the liquid-gas surface tension of $\mathrm{Bi}_{2} \mathrm{Te}_{3}$ nanofluids, Nanotechnology. 20 (2009) 185702.

[37] B.P. Binks, A. Desforges, D.G. Duff, Synergistic stabilization of emulsions by a mixture of surface-active nanoparticles and surfactant, Langmuir. 23 (2007) 1098-1106.

[38] J. Chinnam, D.K. Das, R.S. Vajjha, J.R. Satti, Measurements of the surface tension of nanofluids and development of a new correlation, Int. J. Therm. Sci. 98 (2015) 68-80.

[39] H. Ranjbar, M.R. Khosravi-Nikou, A. Safiri, S. Bovard, A. Khazaei, Experimental and theoretical investigation on Nano-fluid surface tension, J. Nat. Gas Sci. Eng. 27 (2015) 1806-1813.

[40] M.A. Osman, A. Atallah, Effect of the particle size on the viscoelastic properties of filled polyethylene, Polymer. 47 (2006) 2357-2368.

[41] K. Zazakowny, J. Lewandowska-Łańcucka, J. Mastalska-Popławska, K. Kamiński, A. Kusior, M. Radecka, M. Nowakowska, Biopolymeric hydrogels-nanostructured $\mathrm{TiO}_{2}$ hybrid materials as potential injectable scaffolds for bone regeneration, Colloids Surfaces B Biointerfaces. 148 (2016) 607-614.

[42] Q. Wang, R. Hou, Y. Cheng, J. Fu, Super-tough double-network hydrogels reinforced by covalently compositing with silica-nanoparticles, Soft Matter. 8 (2012) 6048-6056. 
[43] H.J. Li, K. Haraguchi, Mechanical and swelling/de-swelling properties of nanocomposite gel with high clay content, Polym. Prepr. Japan. 55 (2006) 1898-1905.

[44] G.U. Badranova, P.M. Gotovtsev, Y. V. Zubavichus, I.A. Staroselskiy, A.L. Vasiliev, I.N. Trunkin, M. V. Fedorov, Biopolymer-based hydrogels for encapsulation of photocatalytic $\mathrm{TiO}_{2}$ nanoparticles prepared by the freezing/thawing method, J. Mol. Liq. 223 (2016) 1620.

[45] M.L. Peralta Ramos, J.A. González, S.G. Albornoz, C.J. Pérez, M.E. Villanueva, S.A. Giorgieri, G.J. Copello, Chitin hydrogel reinforced with $\mathrm{TiO} 2$ nanoparticles as an arsenic sorbent, Chem. Eng. J. 285 (2016) 581-587.

[46] G.A. Valencia, I.C.F. Moraes, L.H.G. Hilliou, R.V. Lourenço, P.J.D.A. Sobral, Nanocomposite-forming solutions based on cassava starch and laponite: Viscoelastic and rheological characterization, J. Food Eng. 166 (2015) 174-181.

[47] J. Zhang, C.R. Daubert, E. Allen Foegeding, A proposed strain-hardening mechanism for alginate gels, J. Food Eng. 80 (2007) 157-165.

[48] M. Mancini, M. Moresi, R. Rancini, Mechanical properties of alginate gels: Empirical characterisation, J. Food Eng. 39 (1999) 369-378.

[49] C. Michon, C. Chapuis, V. Langendorff, P. Boulenguer, G. Cuvelier, Strain-hardening properties of physical weak gels of biopolymers, Food Hydrocoll. 18 (2004) 999-1005.

[50] W. Wang, X. Zhang, A. Teng, A. Liu, Mechanical reinforcement of gelatin hydrogel with nanofiber cellulose as a function of percolation concentration, Int. J. Biol. Macromol. 103 (2017) 226-233.

[51] S.L. Cook, S.P. Bull, L. Methven, J.K. Parker, V. V. Khutoryanskiy, Mucoadhesion: A food perspective, Food Hydrocoll. 72 (2017) 281-296. 
[52] D.S. Jones, A.D. Woolfson, A.F. Brown, Textural, viscoelastic and mucoadhesive properties of pharmaceutical gels composed of cellulose polymers, Int. J. Pharm. 151 (1997) $223-233$.

[53] A.K. Gaharwar, C.P. Rivera, C.J. Wu, G. Schmidt, Transparent, elastomeric and tough hydrogels from poly(ethylene glycol) and silicate nanoparticles, Acta Biomater. 7 (2011) 4139-4148.

[54] B. Boddupalli, Z.. Mohammed, R. Nath, D. Banji, Mucoadhesive drug delivery system: An overview, J. Adv. Pharm. Technol. Res. 1 (2010) 381-387.

[55] R.B. Gandhi, J.R. Robinson, Oral cavity as a site for bioadhesive drug-delivery, Adv. Drug Deliv. Rev. 13 (1994) 43-74.

[56] M.C. Bourne, Food texture and viscosity: Concept and measurement, 2nd ed., Academic Press, New York, 2002.

[57] M.H. Lau, J. Tang, a T. Paulson, Texture profile and turbidity of gellan/gelatin mixed gels, Food Res. Int. 33 (2000) 665-671.

[58] D. Wu, J. Xu, Y. Chen, M. Yi, Q. Wang, Gum Arabic: A promising candidate for the construction of physical hydrogels exhibiting highly stretchable, self-healing and tensility reinforcing performances, Carbohydr. Polym. 181 (2018) 167-174. 


\section{Figure captions}

Fig. 1. Changes of G' (filled symbols) and G" (open symbols) in stress sweep of SSG (a), SSG-5TiO 2 (b), SSG-10TiO 2 (c), SSG-15TiO 2 (d), SSG-20TiO 2 (e) and SSG-25TiO 2 (f) nanohybrid hydrogels $(f=1 \mathrm{~Hz}$ and $\left.\mathrm{T}=20^{\circ} \mathrm{C}\right)$.

Fig. 2. The Effect of increasing stress amplitude on elastic stress (G'. $\gamma)$ of pure SSG and $\mathrm{TiO}_{2}$ reinforced SSG-based nanohybrid hydrogels.

Fig. 3. Frequency sweeps of G' (filled symbols) and G" (open symbols) for SSG (a), SSG-5TiO 2 (b), SSG-10TiO 2 (c), SSG-15TiO 2 (d), SSG-20TiO 2 (e) and SSG-25TiO 2 (f) nanohybrid hydrogels at LVE region $(\tau=0.1 \mathrm{~Pa})$ and $\mathrm{T}=20^{\circ} \mathrm{C}$.

Fig. 4. The effect of frequency on complex viscosity $\left(\eta^{*}\right)$ of pure SSG and $\mathrm{TiO}_{2}$ reinforced SSG-based nanohybrid hydrogels at $\tau=0.1 \mathrm{~Pa}$ and $\mathrm{T}=20^{\circ} \mathrm{C}$. 
Table 1. Zeta potential, particle size, surface tension and density of sage seed gum dispersion (1\%) and $\mathrm{SSG}^{-\mathrm{TiO}_{2}}$ nanocomposite hydrogels at $25^{\circ} \mathrm{C}$.

\begin{tabular}{|c|c|c|c|c|}
\hline Samples & Particle size (nm) & Zeta potential $(\mathrm{mV})$ & Density $(\mathrm{g} / \mathrm{ml})$ & Surface tension $(\mathrm{mN} / \mathrm{m})$ \\
\hline $\mathrm{TiO}_{2}-\mathrm{NPs}$ & $21 \pm 2.0^{\mathrm{a}}$ & $-12.7 \pm 1.3^{\mathrm{e}}$ & - & - \\
\hline SSG & $277.6 \pm 40.3^{\mathrm{b}}$ & $-53.1 \pm 0.4^{\mathrm{a}}$ & $1.47 \pm 0.01^{\mathrm{a}}$ & $62.2 \pm 0.2^{\mathrm{d}}$ \\
\hline SSG-5TiO 2 & $499.7 \pm 59.2^{\mathrm{c}}$ & $-54.3 \pm 1.0^{\mathrm{a}}$ & $1.45 \pm 0.03^{\mathrm{a}}$ & $58.2 \pm 0.1^{\mathrm{a}}$ \\
\hline SSG-10TiO 2 & $764.9 \pm 52.8^{d}$ & $-48.5 \pm 1.1^{b}$ & $1.49 \pm 0.01^{\mathrm{b}}$ & $64.0 \pm 0.2^{\mathrm{e}}$ \\
\hline SSG- $15 \mathrm{TiO}_{2}$ & $889.4 \pm 46.0^{\mathrm{e}}$ & $-47.9 \pm 0.3^{b}$ & $1.50 \pm 0.02^{\mathrm{b}}$ & $61.6 \pm 0.2^{\mathrm{c}}$ \\
\hline SSG-20TiO 2 & $949.6 \pm 92.4^{\mathrm{e}, \mathrm{f}}$ & $-43.3 \pm 0.6^{c}$ & $1.91 \pm 0.04^{\mathrm{c}}$ & $60.6 \pm 0.2^{\mathrm{b}}$ \\
\hline SSG-25TiO 2 & $1009.1 \pm 25.7^{\mathrm{f}}$ & $-39.7 \pm 1.5^{\mathrm{d}}$ & $2.19 \pm 0.02^{\mathrm{d}}$ & $61.5 \pm 0.3^{c}$ \\
\hline
\end{tabular}

Different letters indicate significant differences between samples at $\mathrm{P}<0.05$ by Duncan test. 
Table 2. Storage modulus $\left(\mathrm{G}_{\mathrm{LVE}}^{\prime}\right)$, Loss modulus $\left(\mathrm{G}_{\mathrm{LVE}}\right)$, complex modulus $\left(\mathrm{G}_{\mathrm{LVE}}^{*}\right)$, loss-tangent $\left(\tan (\delta)_{\mathrm{LVE}}\right)$, dynamic yield stress $\left(\tau_{\mathrm{d}}\right)$ and static yield stress $\left(\tau_{\mathrm{s}}\right)$ in the linear viscoelastic region, flow-point stress $\left(\tau_{\mathrm{f}}\right)$ with corresponding modulus $\left(\mathrm{G}_{\mathrm{f}}\right)$, slope of the loss tangent at $\mathrm{n}$ LVE range $\left(\operatorname{Tan}(\delta)_{\mathrm{s}(\mathrm{n}-\mathrm{LVE})}\right)$, failure stress $\left(\tau_{\mathrm{Fr}}\right)$ and failure strain $\left(\gamma_{\mathrm{Fr}}\right)$ for $1 \%$ dispersion of SSG-based hydrogels $\left(f=1 \mathrm{~Hz}\right.$ and $\left.\mathrm{T}=20^{\circ} \mathrm{C}\right)$.

\begin{tabular}{|c|c|c|c|c|c|c|}
\hline Parameters/Samples & SSG & SSG-5TiO 2 & SSG-10TiO 2 & SSG-15TiO 2 & SSG-20TiO 2 & SSG-25TiO 2 \\
\hline $\mathrm{G}_{\mathrm{LVE}}^{\prime}(\mathrm{Pa})$ & $39.83 \pm 1.2^{\mathrm{a}}$ & $41.91 \pm 1.6^{\mathrm{b}}$ & $45.12 \pm 0.9^{c}$ & $50.56 \pm 3.1^{\mathrm{d}}$ & $54.39 \pm 1.5^{\mathrm{e}}$ & $55.28 \pm 2.2^{\mathrm{e}}$ \\
\hline $\mathrm{G}_{\mathrm{LVE}}(\mathrm{Pa})$ & $16.77 \pm 0.6^{\mathrm{a}}$ & $20.66 \pm 0.2^{c}$ & $19.45 \pm 0.4^{\mathrm{b}}$ & $20.41 \pm 0.3^{c}$ & $21.73 \pm 0.5^{\mathrm{d}}$ & $21.62 \pm 0.4^{\mathrm{d}}$ \\
\hline $\mathrm{G}_{\mathrm{LVE}}^{*}(\mathrm{~Pa})$ & $43.21 \pm 1.0^{\mathrm{a}}$ & $46.72 \pm 1.2^{\mathrm{b}}$ & $49.13 \pm 1.0^{c}$ & $54.52 \pm 1.3^{\mathrm{d}}$ & $58.57 \pm 1.1^{\mathrm{e}}$ & $59.35 \pm 0.9^{\mathrm{e}}$ \\
\hline $\operatorname{Tan}(\delta)_{\operatorname{LVE}}$ & $0.42 \pm 0.0^{\mathrm{c}}$ & $0.49 \pm 0.0^{\mathrm{a}}$ & $0.43 \pm 0.0^{\mathrm{b}}$ & $0.40 \pm 0.0^{\mathrm{d}}$ & $0.40 \pm 0.0^{\mathrm{d}}$ & $0.39 \pm 0.0^{\mathrm{d}}$ \\
\hline$\tau_{\mathrm{d}}(\mathrm{Pa})$ & $4.45 \pm 0.2^{\mathrm{a}}$ & $4.57 \pm 0.2^{\mathrm{a}}$ & $3.12 \pm 0.3^{b}$ & $2.13 \pm 0.2^{\mathrm{c}}$ & $1.50 \pm 0.1^{\mathrm{d}}$ & $1.45 \pm 0.1^{\mathrm{d}}$ \\
\hline$\tau_{\mathrm{s}}(\mathrm{Pa})$ & $6.27 \pm 0.2^{\mathrm{b}}$ & $5.89 \pm 0.1^{\mathrm{a}}$ & $6.79 \pm 0.0^{c}$ & $6.92 \pm 0.1^{\mathrm{c}, \mathrm{d}}$ & $7.02 \pm 0.2^{\mathrm{d}}$ & $7.99 \pm 0.1^{\mathrm{e}}$ \\
\hline$\tau_{\mathrm{f}}(\mathrm{Pa})$ & $18.82 \pm 0.4^{\mathrm{d}}$ & $16.60 \pm 0.1^{\mathrm{a}}$ & $17.55 \pm 0.3^{\mathrm{b}}$ & $19.08 \pm 0.2^{\mathrm{d}}$ & $19.40 \pm 0.1^{\mathrm{e}}$ & $18.24 \pm 0.2^{c}$ \\
\hline $\mathrm{G}_{\mathrm{f}}(\mathrm{Pa})$ & $13.64 \pm 0.1^{\mathrm{a}}$ & $13.67 \pm 0.2^{\mathrm{a}}$ & $13.49 \pm 0.1^{\mathrm{a}}$ & $15.21 \pm 0.3^{\mathrm{b}}$ & $15.49 \pm 0.2^{\mathrm{b}}$ & $15.45 \pm 0.3^{\mathrm{b}}$ \\
\hline$\gamma_{\mathrm{Fr}}(\%)$ & $92.29 \pm 2.8^{\mathrm{a}}$ & $91.15 \pm 2.2^{\mathrm{a}}$ & $150.73 \pm 3.4^{c}$ & $159.92 \pm 3.1^{\mathrm{d}}$ & $144.02 \pm 1.9^{c}$ & $109.48 \pm 3.7^{\mathrm{b}}$ \\
\hline$\tau_{\mathrm{Fr}}(\mathrm{Pa})$ & $24.13 \pm 0.7^{\mathrm{a}}$ & $24.58 \pm 0.2^{\mathrm{a}, \mathrm{b}}$ & $26.51 \pm 0.3^{c}$ & $27.30 \pm 0.1^{\mathrm{d}}$ & $28.02 \pm 0.4^{\mathrm{d}}$ & $25.51 \pm 0.2^{\mathrm{b}}$ \\
\hline $\operatorname{Tan}(\delta)_{\mathrm{s}(\mathrm{n}-\mathrm{LVE})}$ & $0.41 \pm 0.0^{\mathrm{a}}$ & $0.44 \pm 0.1^{\mathrm{a}}$ & $0.64 \pm 0.0^{\mathrm{b}}$ & $1.51 \pm 0.1^{\mathrm{c}}$ & $2.03 \pm 0.1^{\mathrm{d}}$ & $1.48 \pm 0.0^{\mathrm{c}}$ \\
\hline
\end{tabular}

Means followed by the different letters in the same rows are significantly different at $\mathrm{P}<0.05$ by Duncan test. 
Table 3. Storage modulus $\left(\mathrm{G}^{\prime}\right)$, viscous modulus $\left(\mathrm{G}^{\prime \prime}\right)$, loss-tangent $(\tan \delta)$, complex modulus $\left(\mathrm{G}^{*}\right)$, complex viscosity $\left(\eta^{*}\right)$ at $f=1 \mathrm{~Hz}$, slope of complex viscosity $\left(\eta^{*}\right.$ s) foe $1 \%$ dispersion of sage seed gum (SSG) and SSG-TiO ${ }_{2}$ hydrogels at $\tau=0.1 \mathrm{~Pa}$ and $\mathrm{T}=20^{\circ} \mathrm{C}$.

\begin{tabular}{|c|c|c|c|c|c|c|}
\hline Parameters/Samples & $\mathrm{SSG}$ & SSG-5TiO 2 & SSG-10TiO 2 & SSG-15TiO 2 & $\mathrm{SSG}-20 \mathrm{TiO}_{2}$ & SSG-25TiO 2 \\
\hline $\mathrm{G}_{1 \mathrm{~Hz}}^{\prime}(\mathrm{Pa})$ & $35.9 \pm 2.1^{\mathrm{a}}$ & $34.9 \pm 2.1^{\mathrm{a}}$ & $43.5 \pm 1.5^{b}$ & $45.5 \pm 1.0^{\mathrm{b}}$ & $59.1 \pm 1.6^{\mathrm{c}}$ & $51.3 \pm 2.1^{\mathrm{d}}$ \\
\hline $\mathrm{G}^{\prime \prime}{ }_{1 \mathrm{~Hz}}(\mathrm{~Pa})$ & $15.4 \pm 1.2^{\mathrm{a}}$ & $19.0 \pm 1.0^{\mathrm{b}}$ & $18.9 \pm 0.1^{\mathrm{b}}$ & $23.6 \pm 0.4^{\mathrm{c}}$ & $27.4 \pm 1.2^{\mathrm{d}}$ & $23.4 \pm 0.8^{\mathrm{c}}$ \\
\hline $\operatorname{Tan} \delta_{1 \mathrm{~Hz}}$ & $0.42 \pm 0.1^{\mathrm{a}}$ & $0.54 \pm 0.0^{\mathrm{d}}$ & $0.43 \pm 0.1^{\mathrm{b}}$ & $0.52 \pm 0.1^{\mathrm{d}}$ & $0.46 \pm 0.0^{c}$ & $0.45 \pm 0.1^{\mathrm{c}}$ \\
\hline $\mathrm{G}_{1 \mathrm{~Hz}}^{*}(\mathrm{~Pa})$ & $39.1 \pm 1.9^{\mathrm{a}}$ & $39.7 \pm 1.1^{\mathrm{a}}$ & $47.4 \pm 1.3^{\mathrm{b}}$ & $51.2 \pm 1.6^{\mathrm{c}}$ & $65.1 \pm 2.0^{\mathrm{e}}$ & $56.4 \pm 0.9^{d}$ \\
\hline$\eta^{*}{ }_{1 \mathrm{~Hz}}(\mathrm{~Pa} . \mathrm{s})$ & $6.2 \pm 0.2^{\mathrm{a}}$ & $6.3 \pm 0.3^{\mathrm{a}}$ & $7.5 \pm 0.1^{b}$ & $8.2 \pm 0.2^{c}$ & $10.4 \pm 0.3^{\mathrm{e}}$ & $8.9 \pm 0.2^{\mathrm{d}}$ \\
\hline$\eta_{\mathrm{s}}^{*}$ & $-0.82 \pm 0.0^{\mathrm{a}}$ & $-0.80 \pm 0.0^{\mathrm{a}}$ & $-0.86 \pm 0.0^{c}$ & $-0.84 \pm 0.0^{b}$ & $-0.89 \pm 0.0^{\mathrm{d}}$ & $-0.89 \pm 0.0^{\mathrm{d}}$ \\
\hline
\end{tabular}

Means followed by the different letters in the same rows are significantly different at $\mathrm{P}<0.05$ by Duncan test. 
Table 4. Frequency dependence of the elastic and viscose moduli, the Friedrich-Heymann model parameters and the subtraction of average G' from G" for $1 \%$ dispersion of sage seed gum (SSG) and $\mathrm{SSG}-\mathrm{TiO}_{2}$ hydrogels $\left(\tau=0.1 \mathrm{~Pa}, \mathrm{~T}=20^{\circ} \mathrm{C}\right)$.

\begin{tabular}{|c|c|c|c|c|c|c|c|c|c|}
\hline \multirow[b]{2}{*}{ Samples } & \multicolumn{3}{|c|}{$G^{\prime}=K^{\prime} \times(\omega)^{n^{\prime}}$} & \multicolumn{3}{|c|}{$G^{\prime \prime}=K^{\prime \prime} \times(\omega)^{n^{\prime \prime}}$} & \multicolumn{3}{|c|}{$G^{*}=A_{\alpha} \times(\omega)^{\alpha}$} \\
\hline & $K^{\prime}(\mathrm{Pa})$ & $n^{\prime}(-)$ & $\overline{\mathrm{R}^{2}}$ & $K^{\prime \prime}(\mathrm{Pa})$ & $n^{\prime \prime}(-)$ & $\mathrm{R}^{2}$ & $A_{\alpha}\left(\operatorname{Pa} \cdot \operatorname{rad}^{-\alpha} . s^{\alpha}\right)$ & $\alpha(-)$ & $\mathrm{R}^{2}$ \\
\hline SSG & $27.83 \pm 0.5^{\mathrm{a}}$ & $0.28 \pm 0.0^{\mathrm{a}}$ & 0.94 & $5.58 \pm 0.3^{b}$ & $0.52 \pm 0.0^{b}$ & 0.96 & $28.69 \pm 1.5^{\mathrm{a}}$ & $0.29 \pm 0.0^{\mathrm{a}}$ & 0.98 \\
\hline SSG-5TiO 2 & $27.47 \pm 0.2^{\mathrm{a}}$ & $0.27 \pm 0.0^{\mathrm{a}}$ & 0.96 & $5.30 \pm 0.1^{\mathrm{a}}$ & $0.40 \pm 0.0^{\mathrm{c}}$ & 0.90 & $28.04 \pm 1.3^{\mathrm{a}}$ & $0.28 \pm 0.0^{\mathrm{a}}$ & 0.97 \\
\hline SSG-10TiO & $32.55 \pm 0.3^{\mathrm{b}}$ & $0.18 \pm 0.0^{\mathrm{b}}$ & 0.98 & $7.69 \pm 0.4^{\mathrm{d}}$ & $0.39 \pm 0.0^{c}$ & 0.92 & $34.70 \pm 2.0^{\mathrm{b}}$ & $0.24 \pm 0.0^{\mathrm{b}}$ & 0.95 \\
\hline SSG- $15 \mathrm{TiO}_{2}$ & $37.91 \pm 0.6^{\mathrm{c}}$ & $0.16 \pm 0.0^{c}$ & 0.99 & $10.23 \pm 0.3^{\mathrm{e}}$ & $0.26 \pm 0.0^{\mathrm{e}}$ & 0.94 & $39.36 \pm 0.9^{\mathrm{d}}$ & $0.17 \pm 0.0^{\mathrm{c}}$ & 0.96 \\
\hline SSG-20TiO & $46.69 \pm 0.5^{\mathrm{d}}$ & $0.11 \pm 0.0^{\mathrm{d}}$ & 0.96 & $16.84 \pm 0.6^{\mathrm{f}}$ & $0.36 \pm 0.0^{\mathrm{d}}$ & 0.96 & $50.46 \pm 1.3^{\mathrm{e}}$ & $0.17 \pm 0.0^{\mathrm{c}}$ & 0.98 \\
\hline SSG-25TiO 2 & $37.02 \pm 0.4^{\mathrm{c}}$ & $0.16 \pm 0.0^{c}$ & 0.96 & $6.36 \pm 0.2^{c}$ & $0.58 \pm 0.0^{\mathrm{a}}$ & 0.96 & $37.12 \pm 1.4^{\mathrm{c}}$ & $0.16 \pm 0.0^{c}$ & 0.96 \\
\hline
\end{tabular}

Means followed by the different letters in the same columns are significantly different at $\mathrm{P}<0.05$ by Duncan test. 


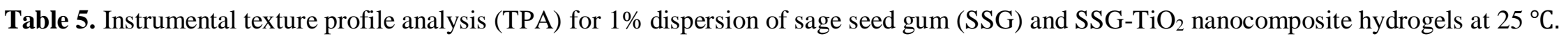

\begin{tabular}{|c|c|c|c|c|c|c|}
\hline Parameters/Samples & SSG & SSG-5TiO ${ }_{2}$ & SSG-10TiO 2 & SSG-15TiO 2 & SSG-20TiO 2 & $\mathrm{SSG}^{25 \mathrm{TiO}_{2}}$ \\
\hline Hardness (g) & $255.1 \pm 3.2^{\mathrm{b}}$ & $267.0 \pm 2.6^{\mathrm{c}}$ & $320.4 \pm 5.7^{\mathrm{d}}$ & $325.6 \pm 6.1^{\mathrm{d}}$ & $307.2 \pm 3.8^{c}$ & $246.1 \pm 5.4^{\mathrm{a}}$ \\
\hline Cohesiveness (-) & $0.68 \pm 0.01^{\mathrm{c}}$ & $0.63 \pm 0.01^{\mathrm{b}}$ & $0.62 \pm 0.02^{\mathrm{b}}$ & $0.56 \pm 0.01^{\mathrm{a}}$ & $0.60 \pm 0.02^{\mathrm{b}}$ & $0.62 \pm 0.03^{\mathrm{b}}$ \\
\hline Adhesiveness (mJ) & $12.5 \pm 0.5^{\mathrm{c}}$ & $11.2 \pm 0.3^{b}$ & $13.2 \pm 0.1^{\mathrm{d}}$ & $13.8 \pm 0.2^{\mathrm{e}}$ & $12.3 \pm 0.4^{\mathrm{c}}$ & $10.3 \pm 0.3^{\mathrm{a}}$ \\
\hline Springiness $(\mathrm{cm})$ & $0.93 \pm 0.03^{\mathrm{a}}$ & $1.12 \pm 0.01^{\mathrm{d}}$ & $1.13 \pm 0.03^{\mathrm{d}}$ & $1.03 \pm 0.03^{\mathrm{c}}$ & $0.97 \pm 0.01^{\mathrm{b}}$ & $0.92 \pm 0.01^{\mathrm{a}}$ \\
\hline Gumminess (g) & $173.1 \pm 4.0^{\mathrm{b}}$ & $169.2 \pm 3.1^{\mathrm{b}}$ & $199.2 \pm 2.8^{\mathrm{d}}$ & $183.6 \pm 2.0^{\mathrm{c}}$ & $185.7 \pm 2.2^{\mathrm{c}}$ & $152.5 \pm 3.6^{\mathrm{a}}$ \\
\hline Apparent elastic modulus (g/s) & $106.4 \pm 2.4^{\mathrm{b}}$ & $123.9 \pm 3.3^{\mathrm{c}}$ & $136.0 \pm 4.2^{\mathrm{d}}$ & $177.6 \pm 3.9^{\mathrm{f}}$ & $142.5 \pm 2.0^{\mathrm{e}}$ & $103.9 \pm 2.7^{\mathrm{a}}$ \\
\hline
\end{tabular}

Means followed by the different letters in the same rows are significantly different at $\mathrm{P}<0.05$ by Duncan test. 

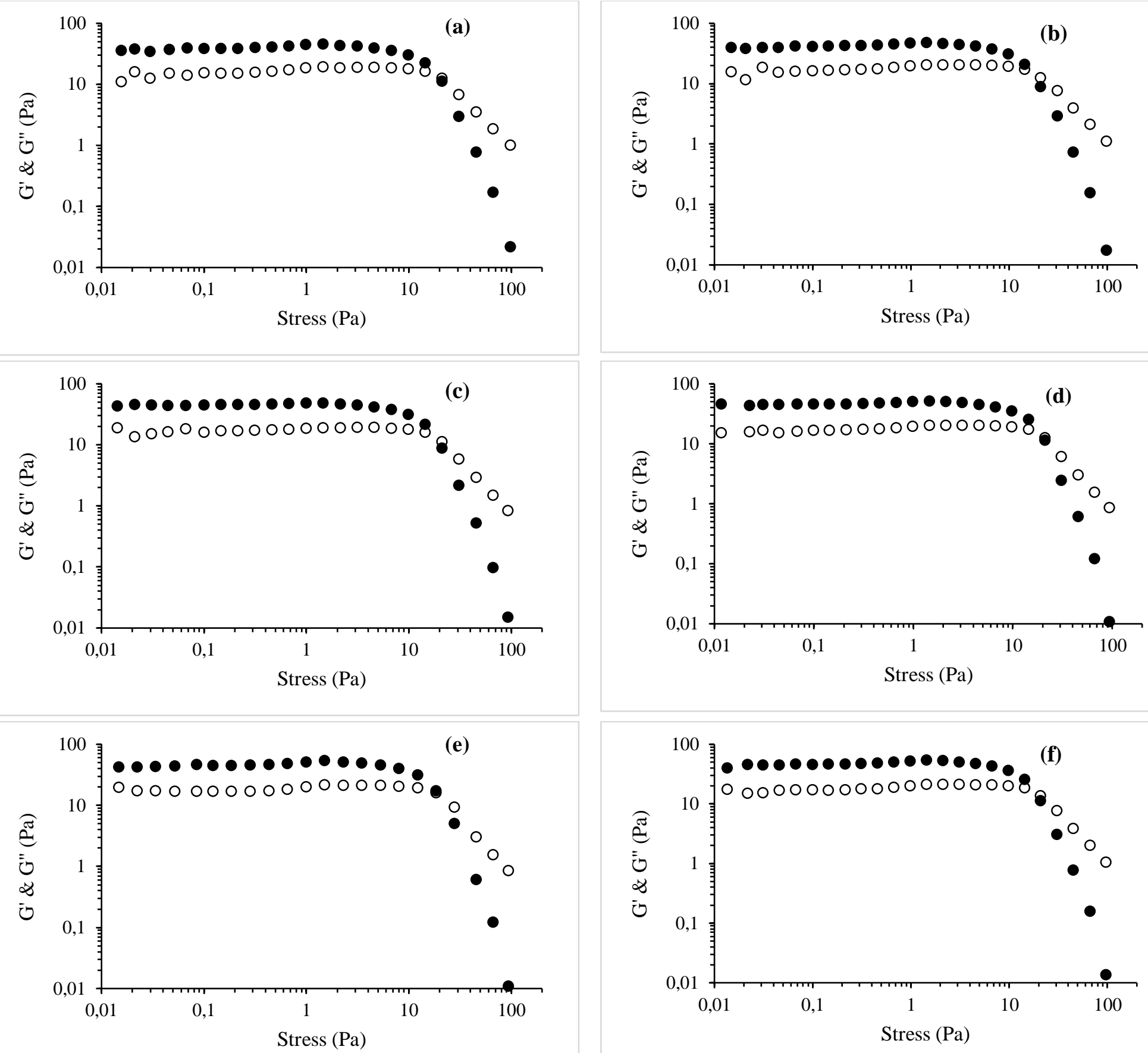

Fig. 1. Changes of G' (filled symbols) and G" (open symbols) in stress sweep of SSG (a), SSG-5TiO 2 (b), SSG-10TiO 2 (c), SSG-15TiO 2 (d), SSG-20TiO 2 (e) and SSG-25TiO 2 (f) nanohybrid hydrogels $(f=1 \mathrm{~Hz}$ and $\mathrm{T}=20^{\circ} \mathrm{C}$ ). 


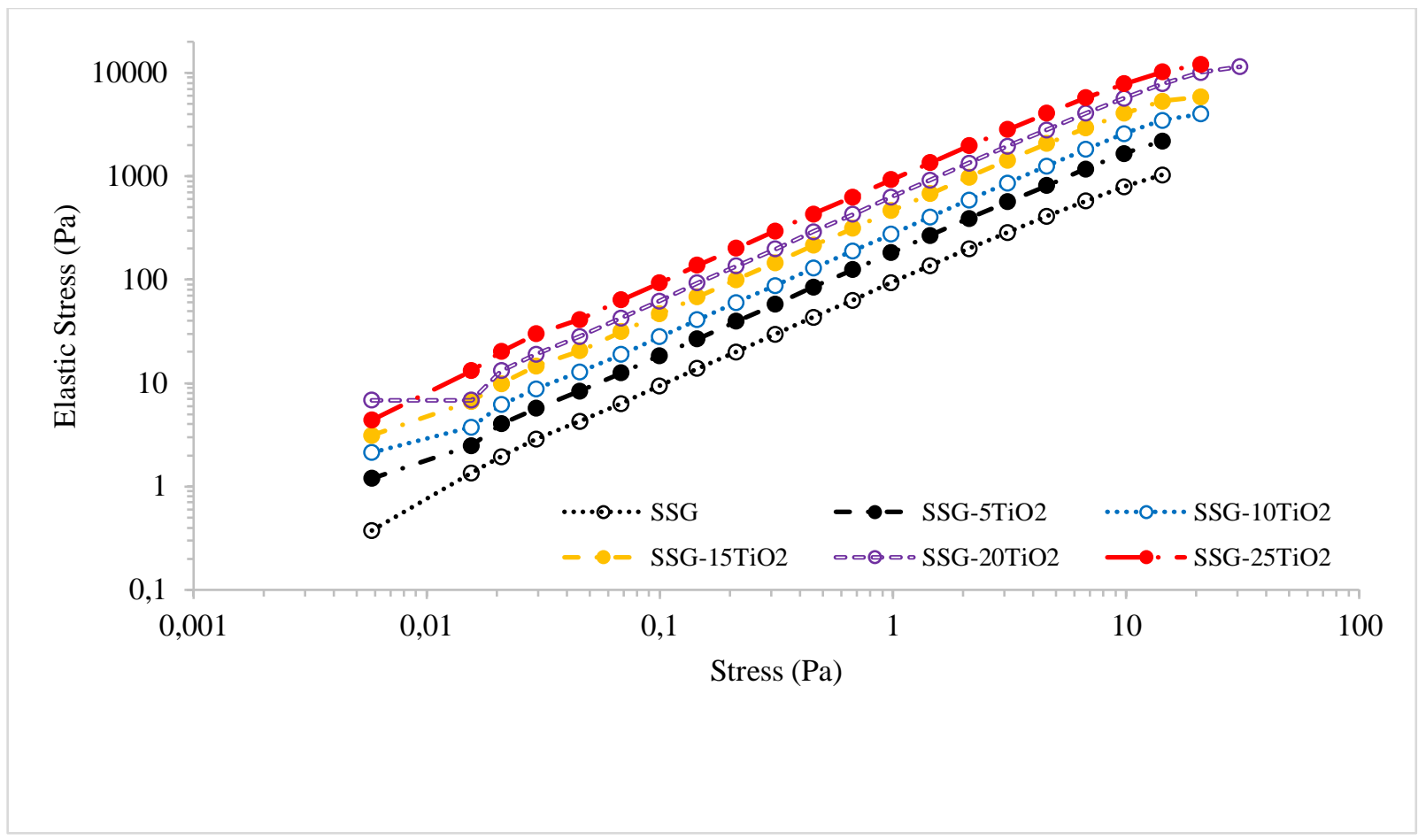

Fig. 2. The Effect of increasing stress amplitude on elastic stress $\left(G^{\prime} \cdot \gamma\right)$ of pure SSG and $\mathrm{TiO}_{2}$ reinforced SSG-based nanohybrid hydrogels. 

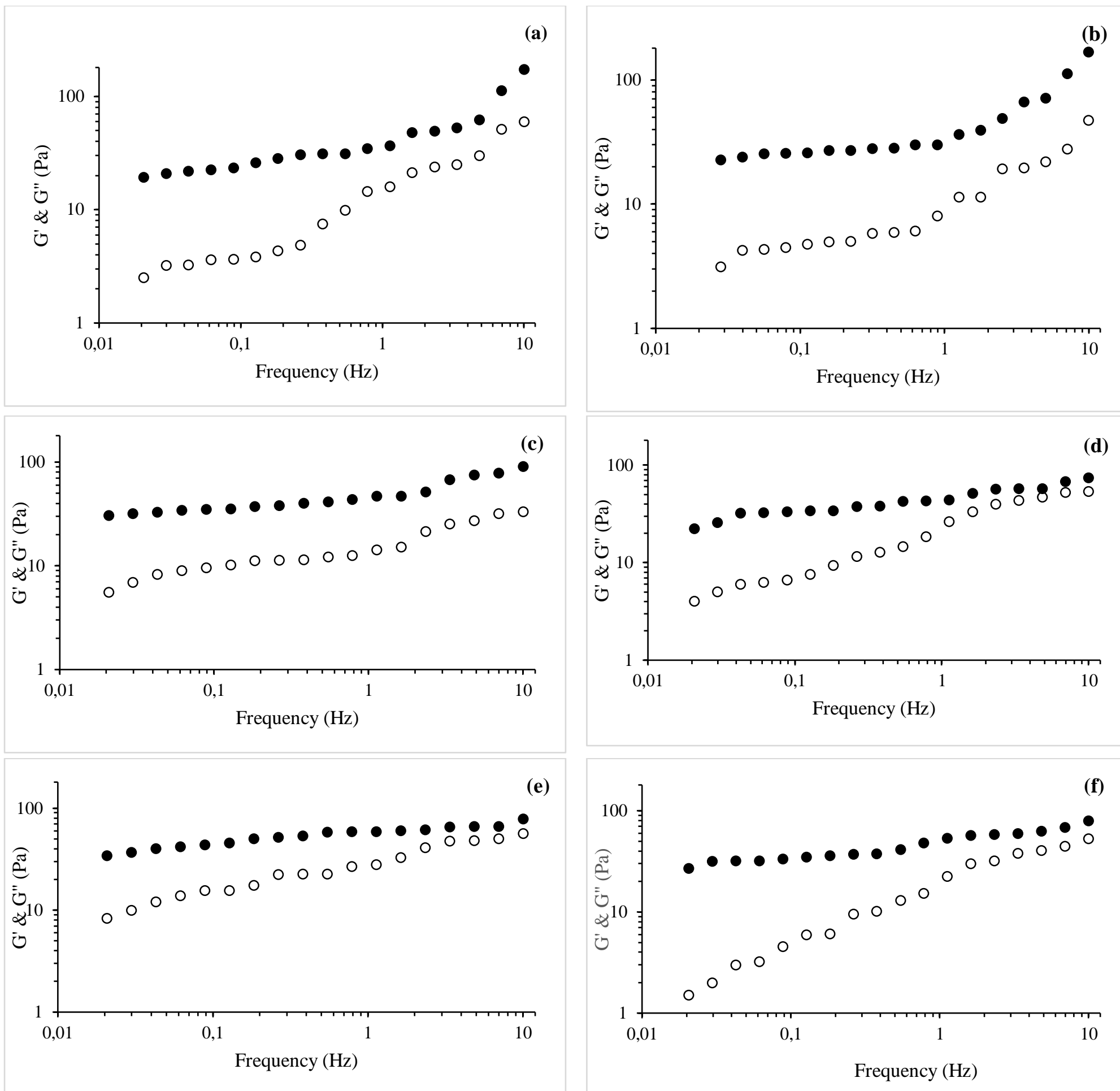

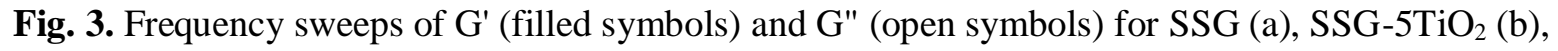

SSG-10TiO 2 (c), SSG-15TiO 2 (d), SSG-20TiO 2 (e) and SSG-25TiO 2 (f) nanohybrid hydrogels at LVE region $(\tau=0.1 \mathrm{~Pa})$ and $\mathrm{T}=20^{\circ} \mathrm{C}$. 


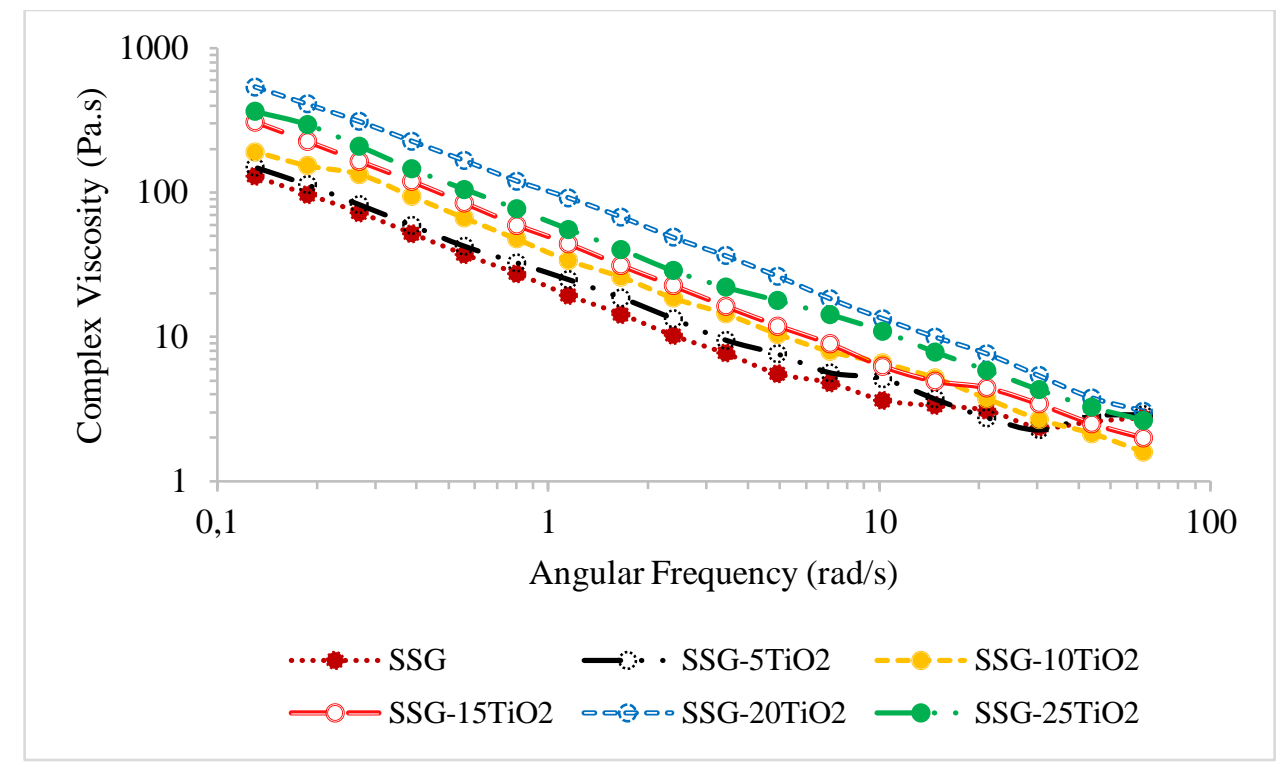

Fig. 4. The effect of frequency on complex viscosity $\left(\eta^{*}\right)$ of pure SSG and $\mathrm{TiO}_{2}$ reinforced SSG-based nanohybrid hydrogels at $\tau=0.1 \mathrm{~Pa}$ and $\mathrm{T}=20^{\circ} \mathrm{C}$. 